UPPSALA

UNIVERSITET

\title{
Resistance and resilience of microbial communities -temporal and spatial insurance against perturbations
}

\section{Didier Ludovic Baho}

Degree project in biology, Master of science (1 year), 2010

Examensarbete i biologi $30 \mathrm{hp}$ till magisterexamen, 2010

Biology Education Centre and Limnology, Uppsala University

Supervisors: Hannes Peter and Lars Tranvik 


\section{Content}

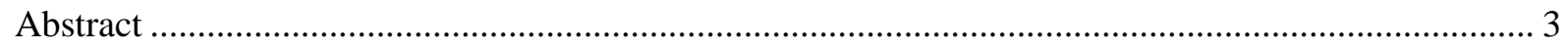

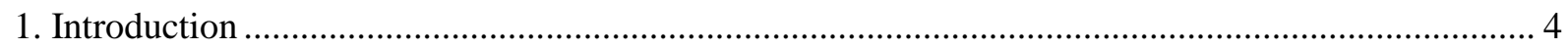

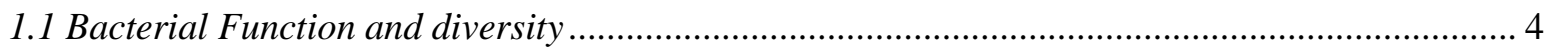

1.2 Factor affecting freshwater bacterial community composition .................................................... 5

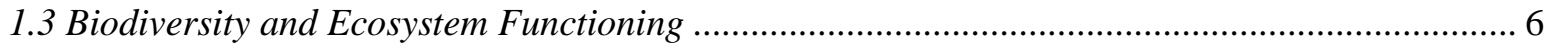

1.4 Ecosystem resilience and resistance …..................................................................................... 7

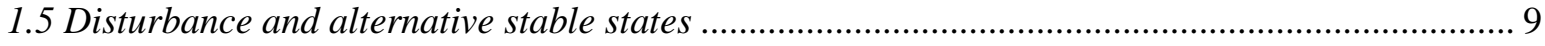

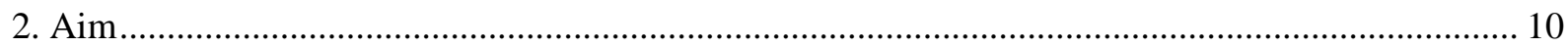

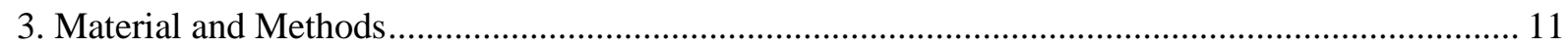

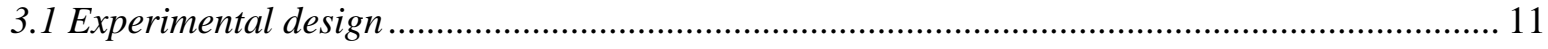

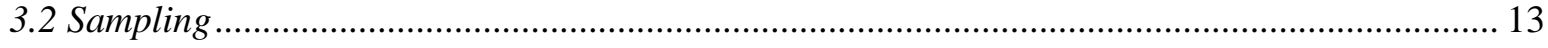

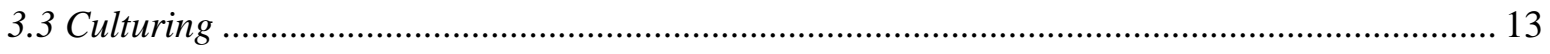

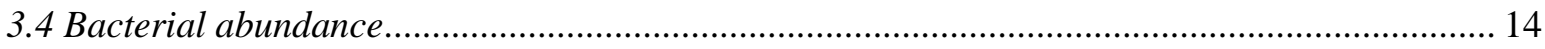

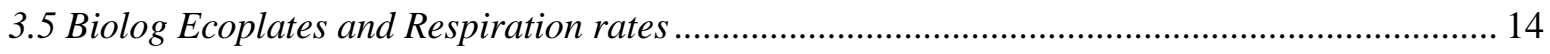

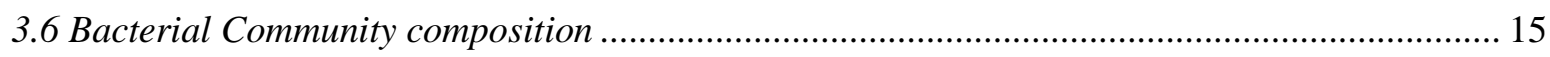

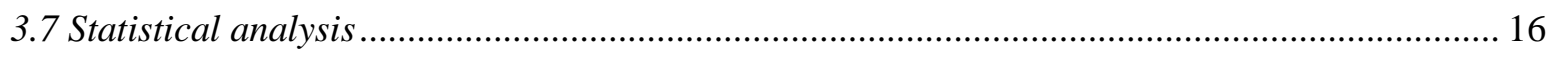

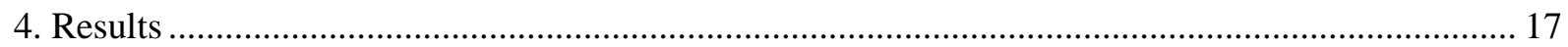

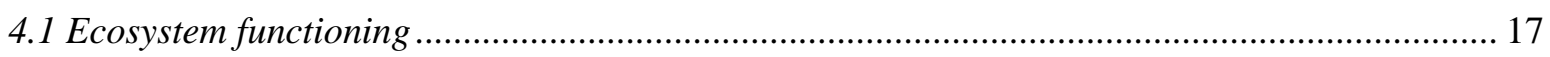

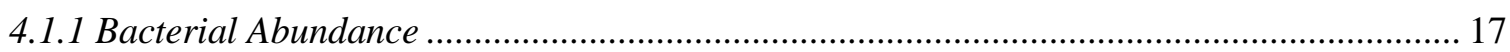

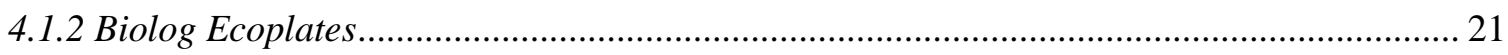

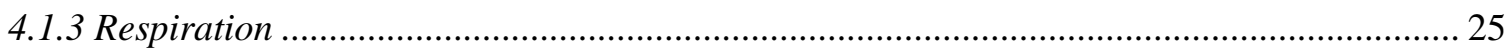

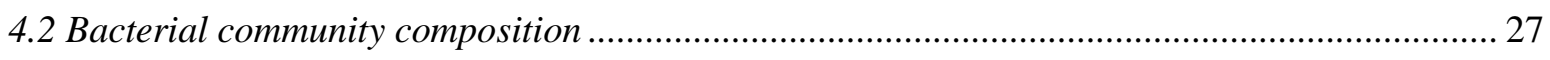

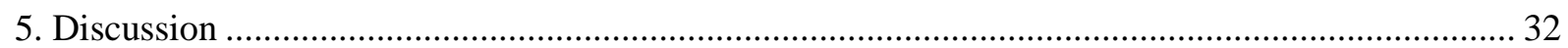

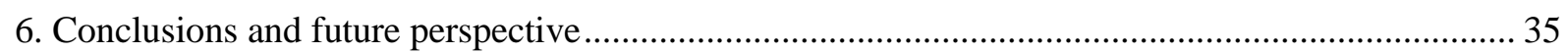

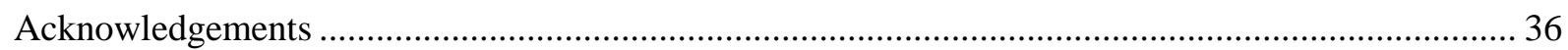

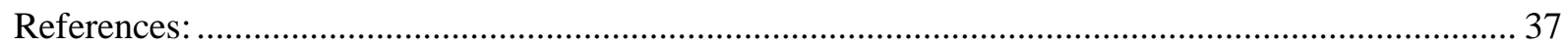




\begin{abstract}
Bacterial communities are fundamental components of many processes occurring in aquatic ecosystems, since through microbial activities substantial amount of matter and energy is transferred from a pool of DOC to higher trophic levels. Previous studies highlighted the beneficial effects of diversity on ecosystem functioning, however studies on the resistance and resilience in microbial communities are scarce. Similarly, studies focusing on factors that might improve resistance or resilience of communities such as the influence of refuges are equally missing, although an understanding of the underlying mechanisms could be very useful in the field of conservation management. In this study, chemostat cultures were used to investigate the influence of a spatial and a temporal refuge on bacterioplankton communities' resistance and resilience measured in terms of functioning and community composition after applying a salinity pulse disturbance. Respiration rate and substrate utilization were used to estimate bacterial functioning while community composition was determined by using $\mathrm{T}$ RFLP. The perturbation was found to affect bacterial functioning and community composition. Moreover our findings indicate that the resistance and resilience measured in terms of bacterial functioning and community composition were significantly influenced by the provision of refuges.
\end{abstract}




\section{Introduction}

\subsection{Bacterial Function and diversity}

Bacterial communities are key players in many processes occurring in aquatic ecosystems (e.g Yannarell and Kent 2009). Bacteria, though invisible to the naked eye, are extremely abundant with about 4-6 x $10^{6}$ cells ml $^{-1}$ and involved in crucial transformation of elements in the biogeochemical cycles on Earth (Whitman et al. 1998). Their metabolic capacities sustain a wide range of ecosystem processes and they are critical for nutrients storage and cycling including: Carbon, Phosphorus and Nitrogen (Allison and Martiny 2008). For instances, it has been estimated that the cellular carbon content of bacteria in aquatic habitats accounts for as much as approximately $2.2 \mathrm{Pg} \mathrm{C}$, compared to a total global estimation of 350-550 Pg C (Whitman et al. 1998). The microbial loop concept, where dissolved organic carbon (DOC) is assimilated by heterotrophic bacterioplankton is recognised to be very crucial in aquatic ecosystems (Pernthaler and Posch 2009). The organic carbon assimilated by heterotrophic bacterial is subsequently transferred to higher trophic levels through bacterivorous protists, which in turn are grazed by micro- and macro- zooplankton (Pernthaler and Posch 2009).

Despite their ecological importance, the extent of the bacterial diversity is largely unknown (Curtis et al. 2006; Pedrós-Alió 2006). The lack of clear species concept in bacteria (as they reproduce asexually and do not fit in the classical definition of species) further complicates the analysis of relationships between bacterial diversity and functioning. Therefore, bacterial "species" are described using operational taxonomic units (OTUs), which are based on gene sequence of certain marker genes (Rosselló-Mora and Amann 2001; Pedrós-Alió 2006). Approximately 10,250 microbial species have been formally identified based on pure culture techniques (Approved Lists of Bacterial Names; http://www.bacterio.cict.fr/number.html, updated on the $5^{\text {th }}$ August 2010). However, culture dependent techniques severely underestimate the extent of environmental microbial diversity. With the advent of culture independent techniques based on the small subunit rRNA marker gene, a new wealth of information about microorganism belonging to the three realms of life: Bacteria, Archaea and Eukarya has been revealed (DeLong and Pace 2001; Pedrós-Alió 2006). Pedrós-Alió (2006) estimated a global diversity of the magnitude $10^{9}$ microbial species might be present based on the trends observed over the past 15 years of microbial diversity studies. Zwart et al. (2002) found that typical freshwater bacteria belonged to the six major divisions: Proteobacteria 
(alpha- and beta-subdivisions), Cytophaga-Flavobacterium-Bacteroides (CFB) group, Actinobacteria, Cyanobacteria, Green non-Sulphur and Verrucomicrobia.

\subsection{Factor affecting freshwater bacterial community composition}

Freshwater bacterial community composition can be affected by different factors, and several studies focussed on environmental factors, which Logue and Lindström (2008) classified into local or regional factors.

Local factors comprise both abiotic and biotic features including: the type of dissolved organic carbon (DOC), ultraviolet light (UV), temperature, salinity, $\mathrm{pH}$, primary productivity and grazing (Logue and Lindström 2008). The nature and quantity of DOC have been found to influence bacterial community composition. Eiler et al. (2003) found that bacterial community composition shifted along the DOC gradient, where alpha-Proteobacteria were found exclusively at low DOC concentrations compared to the other groups which were present along the DOC gradient. Langenheder et al. (2005) pointed out the existence of bacterial communities specialised on DOC of allochthonous origin, and Kirchman et al. (2004) found that the nature of DOC affects the activities of the bacteria involved in the mineralisation of DOC. Bacteria are particular vulnerable to UV radiation as the latter can damage DNA, cellular proteins and lipids (Agogué et al. 2005). In addition, Warnecke et al. (2005) found that UV radiation also affects the community composition by selecting species that are resistant. Yannarell et al. (2003) showed that seasonality in temperature can affect bacterioplankton communities where more intense biological activity occurs during summer. Salinity has been found to affect the community composition either directly by imposing physiological constraints (del Giorgio and Bouvier 2002) or indirectly by altering the molecular structure of DOC (de Haan et al. 1987 cited in Logue and Lindström 2008). Moreover, Lindström and Leskinen (2002) found that $\mathrm{pH}$ can affect bacterial community composition. Gradient in primary productivity can also influence bacterial community composition. For instance, Horner-Devine et al. (2003) found that alpha-proteobacteria responded positively along primary productivity whereas no relationship was observed for beta-proteobacteria. Grazers (heterotrophic nanoflagellates) and viruses are known to be the major causes of bacterial mortality, the estimated daily bacterial mortality caused by grazer and viruses ranges from 5 to $250 \%$ and 5 to $50 \%$, respectively (Miki and Jacquet 2008). Grazing can influence community composition through size-selective predation where only a 
subset of the community is potentially vulnerable (Jürgens and Matz 2002), on the other hand viruses being host-specific can regulate competition by keeping superior groups in the community in check thereby promoting coexistence of competitively weaker population (Weinbauer and Rassoulzadegan 2004). The impact of viruses is known as 'killing the winner' where viral infections is supposed to sustain larger bacterial diversity by preventing dominant population from monopolising limited resources (Weinbauer and Rassoulzadegan 2004; Winter et al. 2010).

Community composition can also be shaped by regional factors, more precisely through dispersal of cells which might have a 'rescue effect' by preventing local extinction of some groups which are vulnerable to local factors (Logue and Lindström 2008).

The recognition that community composition can be shaped by the interactions occurring at two different spatial scales (by the combination local and regional factors) developed into a theoretical framework called the metacommunity concept (Leibold et al. 2004; Logue and Lindström 2008). A metacommunity can be defined as the connection of different local communities linked by the dispersal of potentially interactive species (Wilson 1992), whereas the metacommunity concept focus on how the interaction between regional and local factors shape the assembly and maintenance of communities (Leibold et al. 2004).

\subsection{Biodiversity and Ecosystem Functioning}

The term ecosystem functioning circumscribes biogeochemical activities through which material and energy are processed and transferred in an ecosystem (Naeem 1998) whereas biodiversity refers to the taxonomic, genetic or functional richness present in nature and the simplest measurement of biodiversity is through species richness (Purvis and Hector 2000; Pedrós-Alió 2006). Over the last decades, many studies focused on the relationship between biodiversity and ecosystem functioning (Naeem and Li 1997; Loreau 2000; Loreau et al. 2001; Bell et al. 2005; Hooper et al. 2005; Balvanera et al. 2006). Those studies generally outlined the positive effects of biodiversity on ecosystem functioning, however most of them concern terrestrial ecosystems. Two mechanisms, complementarity and selection (or sampling) effects, have been proposed by which the biodiversity positively influences ecosystem functioning (Bell et al. 2005; Cardinale et al. 2006). Complementarity implies that the higher the numbers of species in a community, the more complete they use resources 
resulting in a higher average productivity (Bell et al. 2005). In contrast, the selection mechanism implies that species rich communities have a higher probability of containing a species which will have a disproportionately larger effect on productivity (Bell et al. 2005). On the other hand, fewer studies address the effects of microbial diversity on ecosystem functioning, although the same positive relationship was found (Naeem and Li 1997; Bell et al. 2005). Interestingly microbial communities were also found to exhibit a high degree of functional redundancy (Franklin and Mills 2006). One study carried out by Franklin and Mills (2006) where they manipulated the diversity of sewage microbial communities by using a dilution-to-extinction approach found that functioning was not affect by a reduction in diversity as many bacterial species had the same function.

\subsection{Ecosystem resilience and resistance}

Previous studies outlined the importance of biodiversity on ecosystem functioning, however all ecosystems are bound to experience environmental fluctuations (Naeem and Li 1997; Yachi and Loreau 1999). To understand how natural communities response to environmental changes and ultimately how these responses influence ecosystem functioning represent a major challenge (Descy and Sarmento 2008). Allison and Martiny (2008) elaborated four hypotheses (shown in Figure 1) to explain the behaviour of microbial communities against a disturbance. The first hypothesis considers microbial communities to be resistant where the microbial community composition is unchanged after being disturbed. The second hypothesis focuses on resilience, where the disturbance alters the community composition but the community returns to its original composition. Resilience can be defined as the amount of disturbance that a community or ecosystem can absorb without changing its state (Holling 1973), and it also comprises the capacity of the community to reorganize and renew itself after being subjected to a disturbance (Elmqvist et al. 2003). The third hypothesis is based on functional redundancy where community composition is altered but the community maintains the same function. The fourth hypothesis is that the composition is altered and they performed differently compared to the original community.

Studies concerning resistance and resilience in microbial communities (Griffiths et al. 2000; Wertz et al. 2007; Allison and Martiny 2008(review); Chaer et al. 2009) are scarce and most of these studies focused on the concept of the insurance hypothesis developed by Yachi and Loreau (1999). The insurance hypothesis emphasised that high diversity can buffer the effects 
environmental disturbances where the loss of some species can be compensated by other functionally redundant species (Yachi and Loreau 1999). Later, Griffiths et al. (2000) found evidence for the insurance hypothesis, where they created a gradient of diversity in soil microbial communities and showed that the high diversity treatment was more resilient to a heat shock disturbance. However, the few studies addressing resilience and resistance in microbial communities are insufficient to understand the complexity of the underling processes. Furthermore, factors which might enhance resistance or resilience of microbial communities have not been explored. For instance dispersal between communities might not only influence diversity but can equally be important to buffer (resistance and resilience) the effects of disturbances, similarly the provision of colonizing surfaces to microbial communities might influence resistance or resilience. These two factors (dispersal and colonisation surfaces) can be considered as refuges for microbial communities.

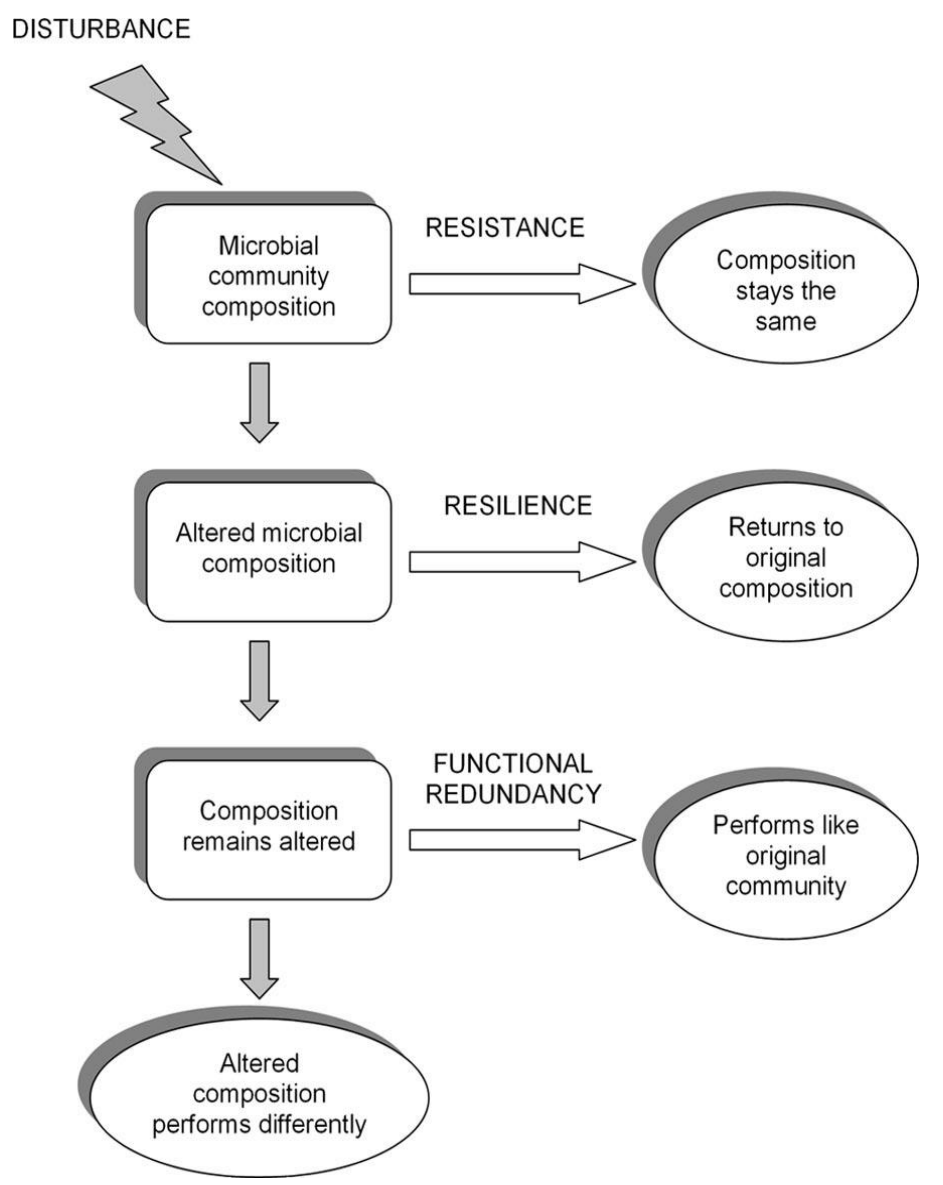

Figure 1. The possible ways how microbial community might respond after a disturbance. Source: Allison and Martiny (2008) reproduced with the permission of the National Academy of Sciences of the United States of America, copyright 2008. 


\subsection{Disturbance and alternative stable states}

Disturbances can be categorized into two types: pulse disturbances, which are short lasting changes and do not have a prolonged effect compared to press disturbance which have a long lasting effect. Natural disturbances tend to occur as pulse disturbances whereas press disturbances are often the results of anthropogenic activities (Glasby and Underwood 1996, Bengtsson et al. 2003).

The concept of ecosystem resilience developed by Holling (1973) recognised the complexity of ecosystems where functionally different (alternative) stable states or multiple stable domains exist and that disturbances can induce the system to move from one stable state to another (Scheffer et al. 2001; Bengtsson et al. 2003). So far there is no strict definition of alternative stable states (Petraitis and Dudgeon 2004), however the concept of alternative stable state can be explained using the ball and cup model (shown in Figure 2). A perturbation can move the ball and a state is stable when the ball remains in the cup (domain). The ball can subsequently move back to its original domain after the perturbation indicating resilience or the disturbance can move the ball to another domain (Scheffer et al. 2001; Bengtsson et al. 2003; Elmqvist et al. 2003).

Mason et al. (2007) raised some critics about the nature of disturbances and emphasised that press disturbances are not applicable to alternative stable states as the alternative community will simply be the result of long term environmental conditions. 


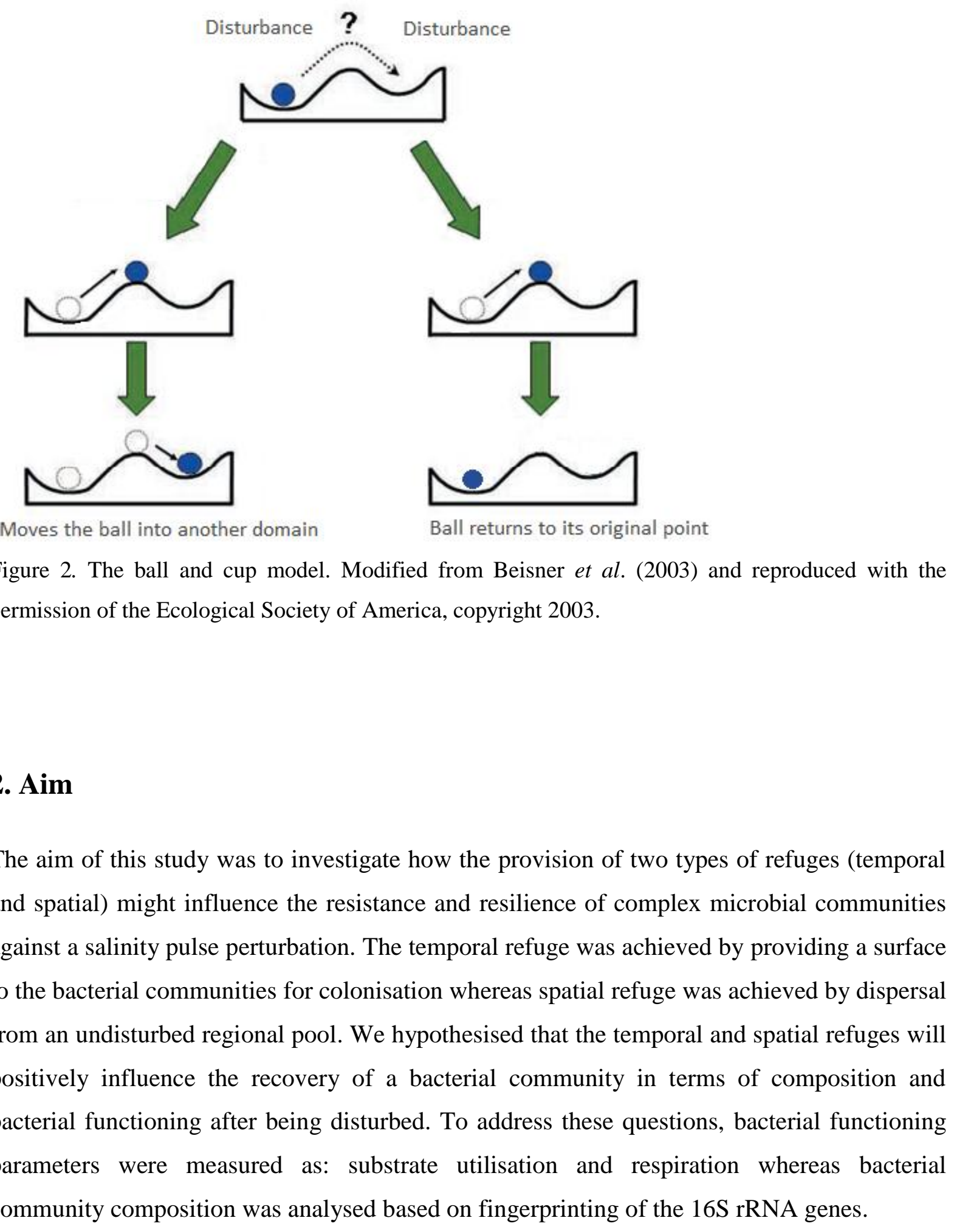




\section{Material and Methods}

\subsection{Experimental design}

In this experiment, we used continuous cultures (chemostats) of bacterial communities with three different treatments: a control (no refuge), a temporal and a spatial refuge against an environmental perturbation. Nine replicates were used for each respective treatment. The chemostat cultures were run with sterilized lake water as a medium and allowed to stabilize for two weeks. Once stabilised, we added salt as a pulse disturbance. Due to the steady inflow of fresh medium (see below, figure $3 \mathrm{a}$ and $3 \mathrm{~b}$ ) the salt (together with bacteria) was removed from the system within 96 hours. The temporal refuge (treatment B) was designed to provide the bacterial communities a surface to be colonized. We used polyethylene biochips (Mutag Biochip $^{\text {TM }}$, Germany) representing an active surface of $1.03 \mathrm{~m}^{2}$. One biochip was added to each of the nine replicates of the temporal treatment. In contrast to the treatment without any refuge (treatment A), cells colonizing the biochips were not removed from the culture. During the perturbation the cells attached to the surface of the biochips in treatment B encounter the same stress as free-floating cells, however they were not removed by the inflow and hence could persist or re-colonize the "pelagic phase" after the perturbation was removed from the system.

The spatial refuge (treatment C) was provided by dispersing cells from an undisturbed regional pool containing the same bacterial communities grown as chemostat cultures. The dispersal rate was adjusted at $19.2 \mu \mathrm{min}^{-1}$, so that $10 \%$ of cells were dispersed daily from the regional pool into the nine replicates representing the spatial refuge treatment. During the perturbation the cells in treatment $\mathrm{C}$ would encounter the same salinity stress, however the undisturbed cells (from the regional pool) would enter the system at a steady rate unlike the two other treatments. 


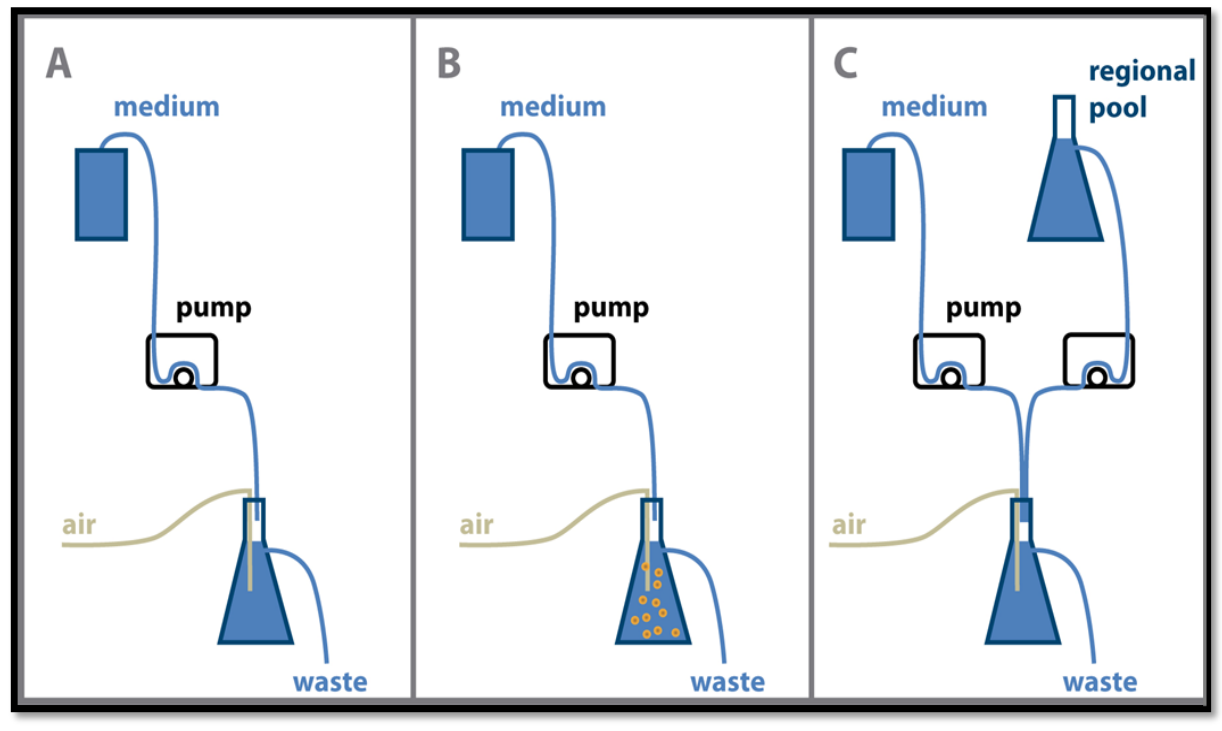

Figure 3a: Experimental design. (A) Chemostat culture with no refuge, (B) Temporal refuge with the active surface and (C) Spatial refuge where active cells are dispersed to the culture from a regional pool.

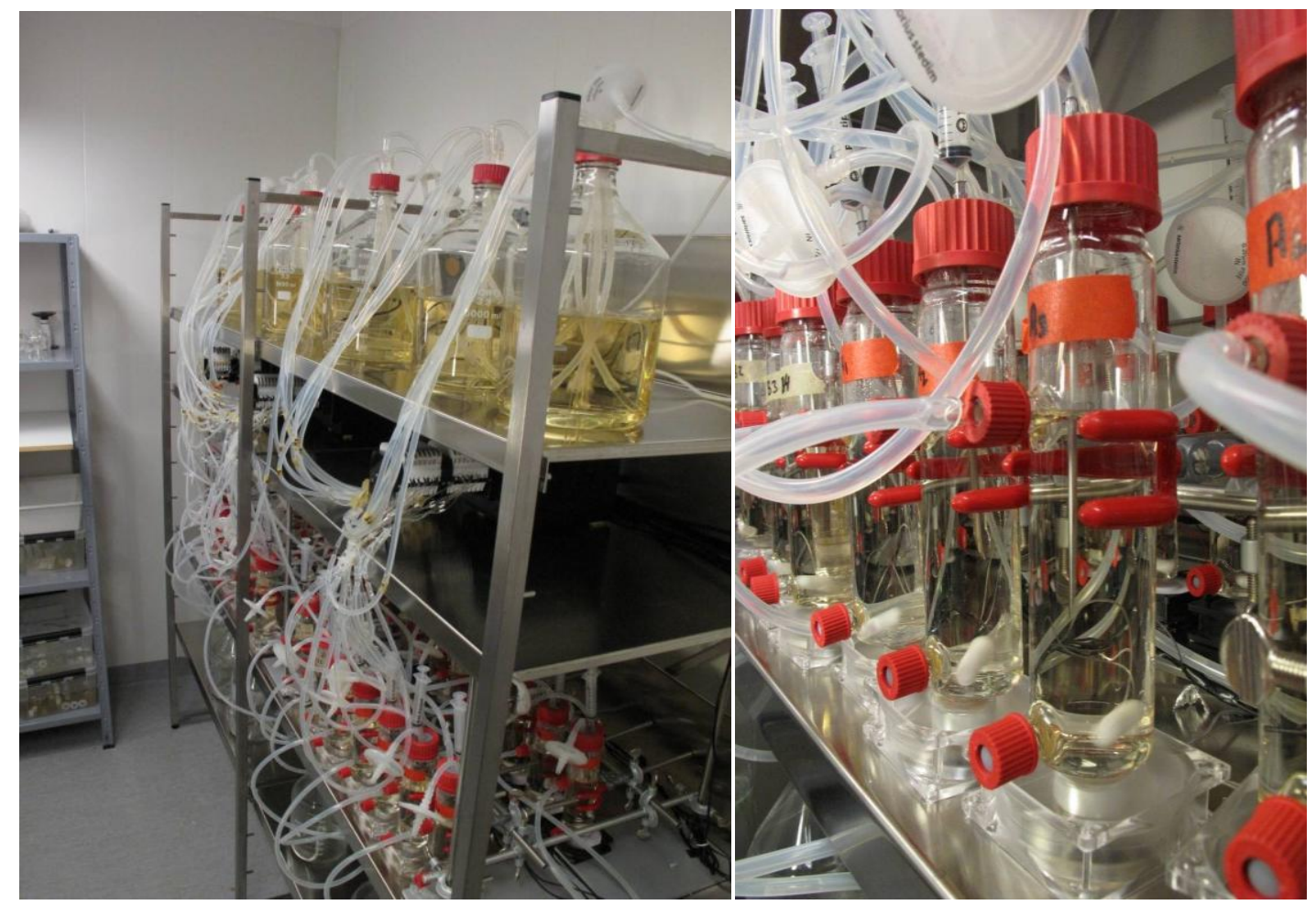

Figure 3b. The experimental setup. 


\subsection{Sampling}

Approximately 300 liters of lake water were samples in spring during the ice break on $14^{\text {th }}$ of April 2010 from Ekoln (Sweden), which is a eutrophic moderately humic lake (Langenheder et al. 2005), for preparing both the medium and an inoculum. Surface water was collected in acid rinsed 25 liters polyethene bottles. The lake water medium was prepared by sequentially pumping the collected water into a coarse filtration cartridge then filtered again using a Zetapor Cartridge of $0.2 \mu \mathrm{m}$ (CUNO, U.S.A). The filtered water was stored at $4^{\circ} \mathrm{C}$ until further treatment. The bacterial communities were isolated from the same lake water after removing eukaryotic predators using a membrane filter of $0.8 \mu \mathrm{m}$ (Pall Corporation, Michigan, U.S.A.) The inoculum was also stored at $4^{\circ} \mathrm{C}$ prior to the start of the experiment. $\mathrm{pH}$ and conductivity of the lake water were measured prior autoclavation. Sterile lake medium was prepared by autoclaving the $0.2 \mu \mathrm{m}$ filtered lake water. One prerequisite for this experiment was that the lake water medium should be free from any spores of microorganism which might survive the autoclavation. This was assured by autoclaving the filtered lake water a second time. After the first autoclaving the water was allowed to cool and stand for 23 days at room temperature to enable any surviving spore to be reactivated, before the second autoclaving. The $\mathrm{pH}$ was observed to rise above 8.49 after the first autoclaving, however it was re-adjusted to the origin lake $\mathrm{pH}$ measurement of 7.60 by adding $1 \%$ of hydrochloric acid solution prior the second autoclaving. After the second autoclaving the sterile lake water medium was stored at $4^{\circ} \mathrm{C}$.

\subsection{Culturing}

Chemostat cultures were used to allow the bacterial communities to grow steadily by maintaining a constant supply of fresh sterilized lake water medium. Simultaneously, cells and media were removed from the system at the same rate. The cultures were incubated at $20^{\circ} \mathrm{C}$ in the dark. The sterile lake medium was pumped from 5 litres bottles and fed into the culture vessels of $200 \mathrm{ml}$ at a constant rate of $96 \mu \mathrm{l} / \mathrm{min}$ using peristaltic pumps (ISMATEC, Glattbrugg, Switzerland). The cultures were stirred constantly with magnetic bars and ventilated through sterile air filters. Syringes $\left(20 \mathrm{ml}\right.$, BD Plastipak ${ }^{\mathrm{TM}}$, U.S.A) were connected to the culture vessels via stainless steel needles and were used to inoculate the bacterial cells, apply the pulse perturbation and for sampling. The sterile lake medium bottles were also 
constantly aerated using an air pump which was connected to a sterile air filter before the air actually reached the medium bottles. All components of the chemostat were autoclaved prior to the start of the experiment.

In the beginning of the experiment, $10 \mathrm{ml}$ of the bacterial inocula were added to each of the $200 \mathrm{ml}$ culture vessels containing the sterile lake medium and were allowed to grow in batch mode. After one week in batch culture mode, the medium was connected to the peristaltic pumps and the cultures were allowed to stabilize for two weeks before a salt $(1.11 \mathrm{ml}$ of 20 ppm of $\mathrm{NaCl}$ ) pulse perturbation was applied. The cultures were maintained in continuous (chemostat) mode for 37 days.

\subsection{Bacterial abundance}

Bacterial abundance was measured on a daily basis during the entire term of the experiment following the protocol by del Giorgio et al. (1996) designed for flow cytometry. Subsamples of $1 \mathrm{ml}$ were taken from the culture vessels, of which $200 \mu \mathrm{l}$ of the samples were fixed with $3 \%$ (final concentration) formaldehyde and store at $4^{\circ} \mathrm{C}$. The cells (DNA) were stained using of $2.5 \mu \mathrm{M}$ of Syto 13 , which is a green fluorescent nucleic acid dye. Subsequently, the cells were enumerated by a flow cytometer (CyFLOW space, Partec $\mathrm{GmbH}$, Germany) using green fluorescence (FL1) and forward light scatter (del Giorgio et al. 1996).

\subsection{Biolog Ecoplates and Respiration rates}

Samples for Biolog Ecoplates and respiration were collected overnight by connecting sterile sampling bottles to the outlet of the chemostat vessels.

We used Biolog Ecoplates to estimate the functional potential of the communities during the batch mode, at two time points before the perturbation and twice after the perturbation. Biolog Ecoplates contain a total of 31 carbon source substrates (three times replicated per plates) and a blank (water) on a transparent 96 well plate. In addition, each well contained a tetrazolium salt, which produces a coloured (blue) compound when reduced (Garland and Mills 1991). Community level physiological activities were measured colourimetrically as the reduction of tetrazolium salt (Comte and del Giorgio 2009). The Biolog Ecoplates were inoculated with $150 \mu \mathrm{l}$ of the sample in each well (Konopka et al. 1998) and incubated at $20^{\circ} \mathrm{C}$ in the dark. Colour development (absorbance at $590 \mathrm{~nm}$ ) was measured daily for seven days starting with 
time zero (immediately after inoculating the Biolog Ecoplates), using a microplate reader (Ultra evolution, Tecan, Austria). The colour development for each Biolog Ecoplate was expressed as the average well colour development (AWCD) (Garland and Mills 1991), which was calculated every time that the plates were read. The analysis of the Biolog Ecoplates data were based on both kinetic (rate of substrate utilization measured by the colour development) and single-point reading when the AWCD was similar to a reference absorbance of $0.5( \pm 0.2)$ as suggested by Garland et al. (2001). The kinetic analyses were based on the slopes of the linear phase of the AWCD for seven time points and were corrected for bacterial density at time zero. In contrast the single-point analysis was based on normalized data, where the readings of each well were initially subtracted from then blank (water) then divided by the ACWD of $0.5( \pm 0.2)$.

Bacterial respiration rates were measured as the consumption of oxygen over time. In parallel to the Biolog Plates, samples for respiration were collected at the same frequency; once during the batch mode, at two time points before the perturbation and twice after the perturbation. For this purpose, samples were incubated in air-tight, $17 \mathrm{ml}$ scintillation vials equipped with septa. Those scintillation vials were kept under water at $20^{\circ} \mathrm{C}$ in the dark. A microoptode housed in a steel needle mounted to a $1 \mathrm{ml}$ plastic syringe (PreSens, Germany) was introduced through the septa of the scintillation vials to measure oxygen concentration. We measured oxygen concentration every 48 hours for a week. The microoptode was connected via an optical cable to a microsensor oxygen meter (Microx Tx3, PreSens, Germany). This system measures oxygen concentration by using different luminescent indicators (Kühl 2005), which in contrast to microelectrodes, does have an inherent oxygen consumption (Kühl and Revsbech 2001 cited in Kühl 2005). Respiration rates were estimated as the slopes of the linear regression lines for four time points.

\subsection{Bacterial Community composition}

Bacterial community composition was determined by T-RFLP of the 16S rRNA genes. DNA samples were taken at several time points: three times before the perturbation and four times after the perturbation. $50 \mathrm{ml}$ of samples were collected into a sterile sampling bottle from the outflow of the culture vessels and were filtered on a filter membrane of $0.2 \mu \mathrm{m}$ (Pall, Michigan, U.S.A). Once filtered, the membranes were kept at $-80^{\circ} \mathrm{C}$ prior to DNA extraction. The DNA was extracted and purified from the frozen filters, using the Power Soil DNA 
extraction kit (MoBio Laboratories, California, U.S.A) following the manufacturer's instructions. For polymerase reaction chain (PCR) amplification of the 16s rRNA genes the universal primers 27-forward, labeled with hexachlorofluorescein (HEX) and unlabelled 519reversed primers were used. For each sample a $50 \mu \mathrm{L}$ PCR reaction was used, consisting of

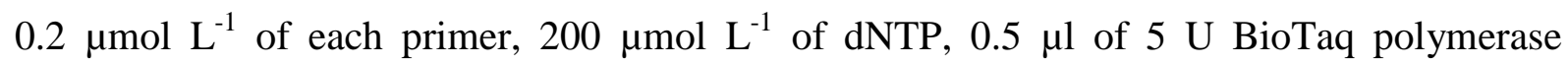
buffered with $50 \mathrm{mmol} \mathrm{L}^{-1} \mathrm{MgCl}_{2}$ and $5 \mu \mathrm{l}$ of $10 \mathrm{xNH} 4$ buffer (Invitrogen, U.S.A). Samples were amplified using a MyGene MG 96 Thermocycler (Longene Scientific Instruments, Hangzhou, China) employing an initial denaturation at $98^{\circ} \mathrm{C}$ for 3 minutes, 28 cycles: of denaturation at $98^{\circ} \mathrm{C}$ for 30 seconds, annealing at $50^{\circ} \mathrm{C}$ for 30 seconds and extension at $72^{\circ} \mathrm{C}$ for 30 seconds, followed by a final 7 minutes extension step at $72^{\circ} \mathrm{C}$. The PCR products were subsequently purified using MultiScreen PRC $\mu 96$ plates (Millipore). Bands of the PCR products were assessed on $1 \%$ agarose gel stained with GelRed (Biotium, California, U.S.A). Samples producing extra bands were subsequently purified, by using a gel extraction kit (QIAquick Gel extraction kit, QIAGEN, Germany). After the gel extraction all PCR products were quantified using Quant-iT ${ }^{\mathrm{TM}}$ PicoGreen ${ }^{\circledR}$ double stranded DNA kit (Invitrogen, U.S.A). Those PCR products containing slightly higher DNA content were diluted to get approximately the same DNA concentration for all samples. Restriction excisions were done using two restriction enzymes Hinf 1 and Hae 1 (New England Biolabs Incorporation, U.S.A.) following the manufacturer's protocol for 16 hours at $37^{\circ} \mathrm{C}$. The size of the terminal restriction fragments were separated electrophoreticly and determined using a 96 capillary sequencer (Applied Biosystems) using GeneScan mode at the Rudbeck laboratory (Sweden). The size and quantity of terminal restriction fragments (TRFs) were analyzed using GeneMarker software (version 1.70)

\subsection{Statistical analysis}

Most statistical analyses were done using PAST (Paleontological Statistics) Software (Version 2.02) whereas regime shift was analyzed by an algorithm (Version 3.2) developed by Rodionov (2004). The bacterial abundance data before and after the perturbation was analyzed using paired t-test, furthermore regime shift detection analysis was also performed on the bacterial abundance data. The effects of the perturbation on bacterial functioning, more specifically substrate utilization rates and respiration rates, were analysed by using MANOVA. The kinetic data of the Biolog Ecoplates and the bacterial respiration rates for 
each respective treatment were analysed using single factor ANOVA with Tukey's test as post-hoc analysis using Minitab software (version 15, USA). The single-point data of the Biolog Ecoplates were analyzed using multivariate statistics namely Principal Component analysis to explore correlation between the three treatments based on a covariance analysis. Bacterial community composition (T-RFLP) was analyzed using a two-dimensional nonmetric multidimensional scaling (nMDS) with Bray Curtis similarity distance matrices. To analyse shifts in community composition, we used PCA to obtain a single value to be used in the regime shift detection algorithm. We choose the second PCA axis, since the first axis, which explained $45 \%$ of the total variance was related rather to the effect of the duration of the experiment, whereas axis 2 and 3 separated the communities according to the treatment (see results). Axis 2 explained more of the total variance (16\%) compared to axis $3(11 \%)$. We applied the regime shift detection algorithm (Rodionov 2004) for the detection of shifts in mean values using a significance level of 0.05 , a Huber's weight parameter of 6 (default) and a cut-off of 9 (equals the number of replicates to avoid effects of the order of the samples entered in the program).

\section{Results}

\subsection{Ecosystem functioning}

We estimated the effects of the perturbation and the treatments on bacterial functioning. Abundance was used as a proxy for bacterial biomass and oxygen consumption rates was used to determine large-scale ecosystem functions with implications on food webs and the carbon cycle. The utilization of 31 different carbon substrates, as measured by Biolog Eco plates, on the other hand, offers more detailed insights in specific ecosystem processes.

\subsubsection{Bacterial Abundance}

During the seven days of batch mode culture we observed rapid growth of the bacterial communities in all three treatments as well as the regional pool (Figure 4). However, the bacterial abundance for treatment B was approximately $10 \%$ lower compared to the other two treatments, indicating that the bacterial communities were able to colonize the biochips 
thereby reducing the abundance in the "pelagic phase". The abundance reached a plateau (approximately $5.5 \times 10^{6}$ cells $\mathrm{ml}^{-1}$ ) after five days (T5) of incubation.

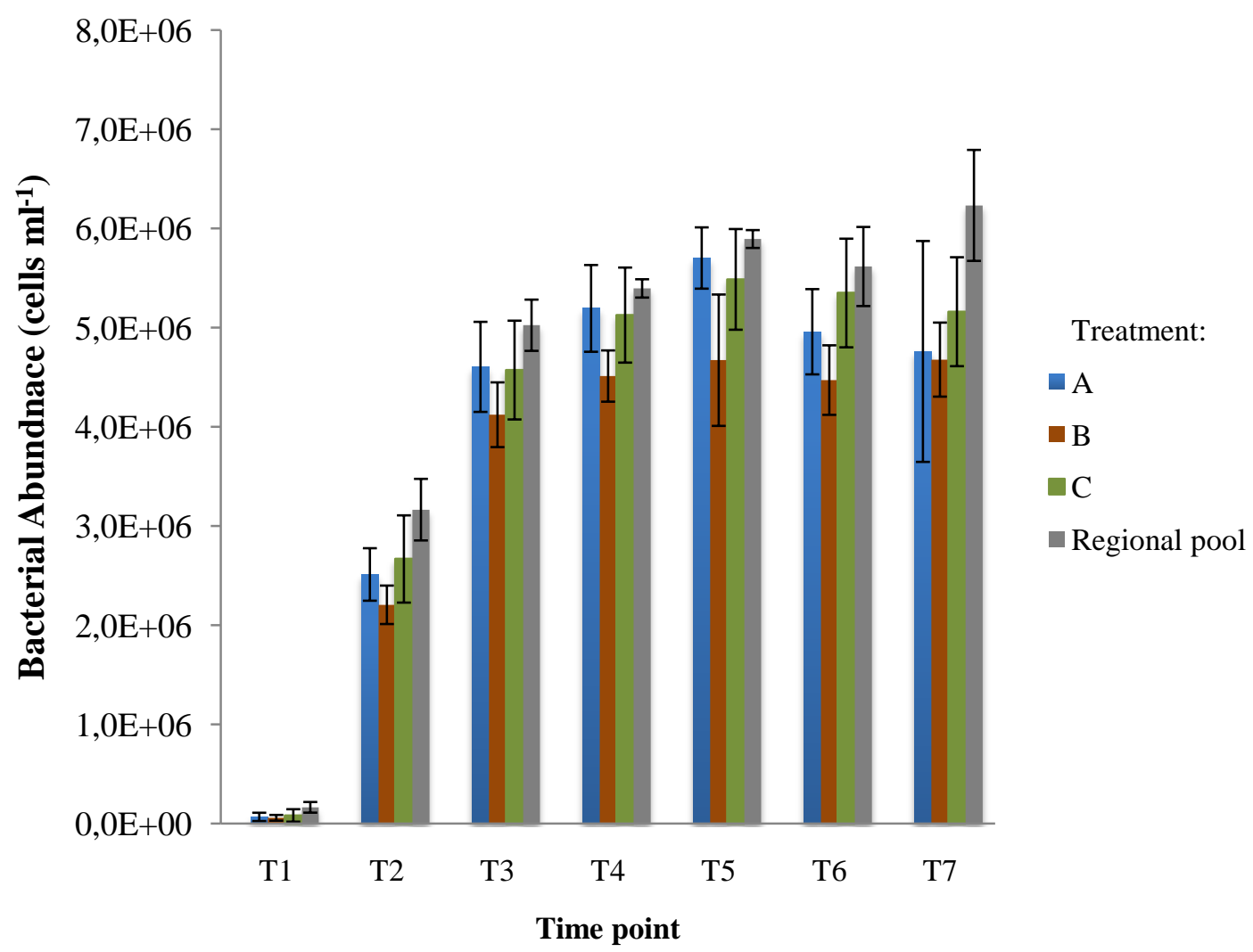

Figure 4. The bacterial abundance for seven days under batch culture mode. Error bars indicate standard deviation.

After one week of incubation in batch culture, we switched to continuous culture (chemostat) mode and the regional pool was connected to treatment C. Subsequently, the abundance in all treatments (Figure 5) dropped to an average value of $1.0 \times 10^{6}$ cells $\mathrm{ml}^{-1}$. The same pattern

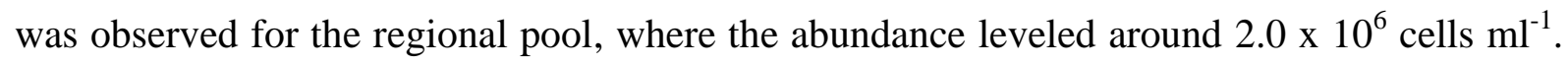
Once the abundance stabilized to an average $1.5 \times 10^{6}$ cells $\mathrm{ml}^{-1}$, the salinity disturbance was induced (T28) on the bacterial communities for the three treatments. 

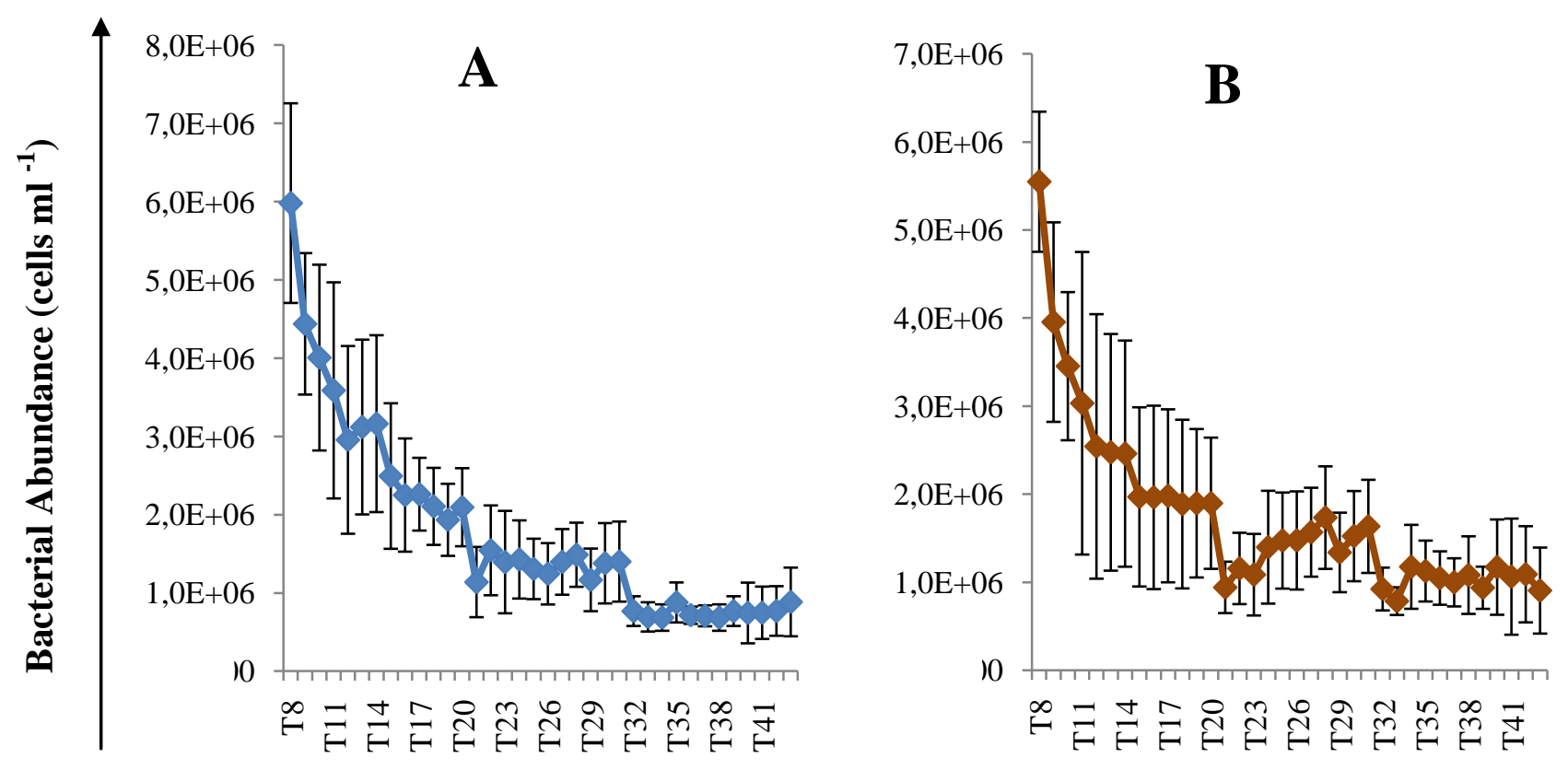

Time point

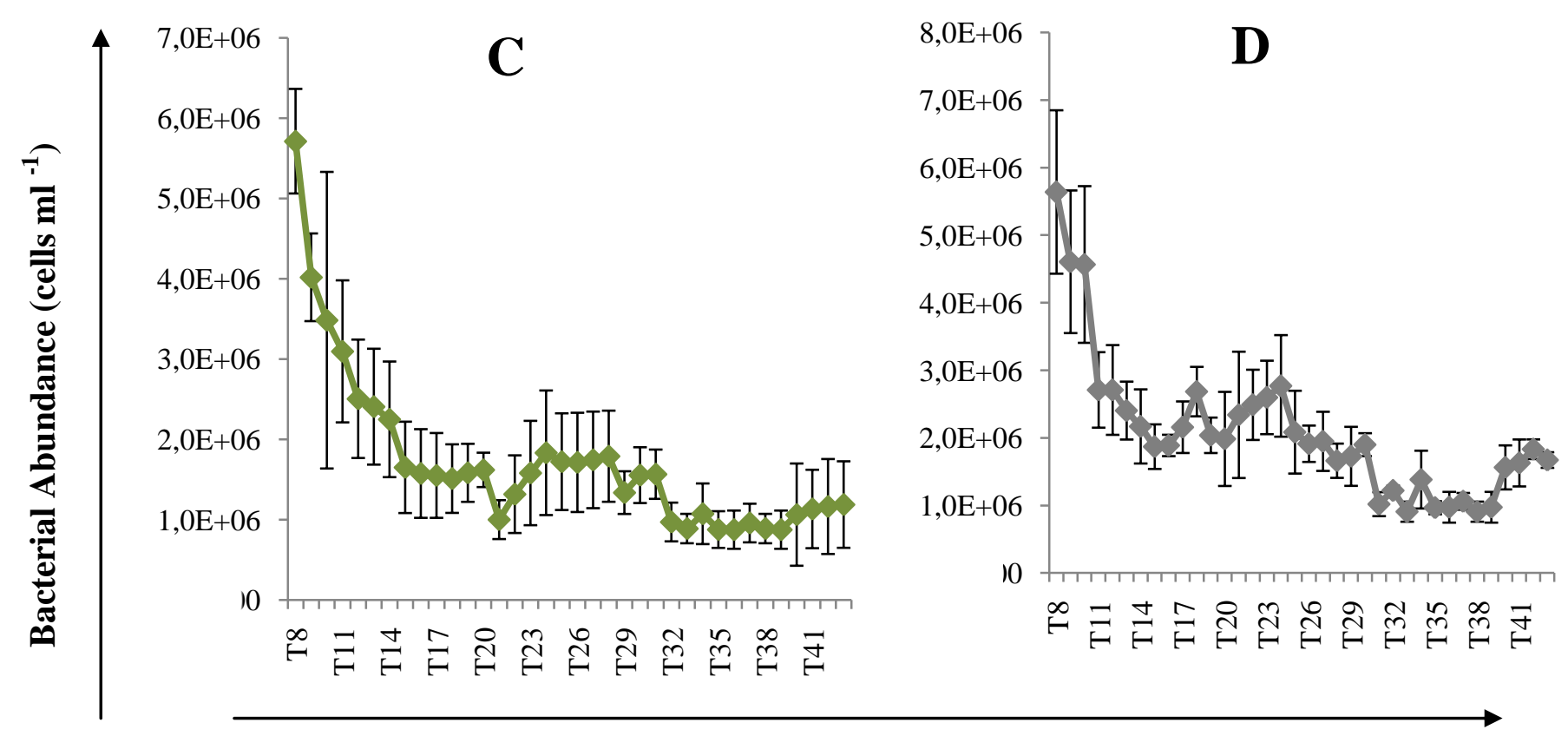

\section{Time point}

Figure 5. The bacterial abundance recorded during the chemostat culture for the three treatments: A (no refuge), B (Temporal refuge) and C (Spatial refuge) whereas D is the abundance for the Regional pool. Error bars indicate standard deviation.

Paired t-test (Table 1) revealed that abundance was significantly affected 24 hours (on T29) after the salt was added in each treatment whereas, no significant differences were observed in the abundance for the undisturbed regional pool. The immediate impact of the perturbation 
was rather small, a more pronounced effect of the perturbation was observed at T32 where the bacterial abundance decreased drastically.

Table 1. The abundance before and after the perturbation with p-values of the Paired t-test

\section{Bacterial abundance cells $\mathbf{~ m l}^{-1}$}

\begin{tabular}{llll} 
Treatment & Before perturbation $^{\mathbf{a}}$ & After perturbation $^{\mathbf{b}}$ & p-value \\
\hline A (control) & $1.49 \times 10^{6} \pm 4.38 \times 10^{5}$ & $1.17 \times 10^{6} \pm 4.27 \times 10^{5}$ & $1.13283 \times 10^{-5}$ \\
B (temporal refuge) & $1.73 \times 10^{6} \pm 5.70 \times 10^{5}$ & $1.34 \times 10^{6} \pm 4.35 \times 10^{5}$ & 0.0003 \\
C (spatial refuge) & $1.79 \times 10^{6} \pm 5.20 \times 10^{5}$ & $1.34 \times 10^{6} \pm 2.43 \times 10^{5}$ & 0.002 \\
Regional pool & $1.66 \times 10^{6} \pm 2.54 \times 10^{5}$ & $1.73 \times 10^{6} \pm 4.37 \times 10^{5}$ & 0.8 \\
\hline
\end{tabular}

${ }^{a}$ time point $\mathrm{T} 28$ before the salt disturbance was added

${ }^{\mathrm{b}}$ time point $\mathrm{T} 29$ the next day after the perturbation was added

Rodionov's (2004) regime shift detection analysis (Figure 6) revealed a strong negative shift occurring on T32 for the three treatments. In contrast no regime shift was observed for the undisturbed regional pool at that specific time point. At time point T40, the regime shift index for both treatments $\mathrm{B}$ and $\mathrm{C}$ increased, indicating a potential shift in abundance to the preperturbation state. Treatment A on the other hand showed a second negative shift on T40, but on T42 a positive shift was observed. The positive shifts which were observed (at T40 for treatments B and C whereas on T42 for treatment A) might indicate that bacterial abundance was increasing however comparable abundance as observed during the pre-perturbation state were not reached.

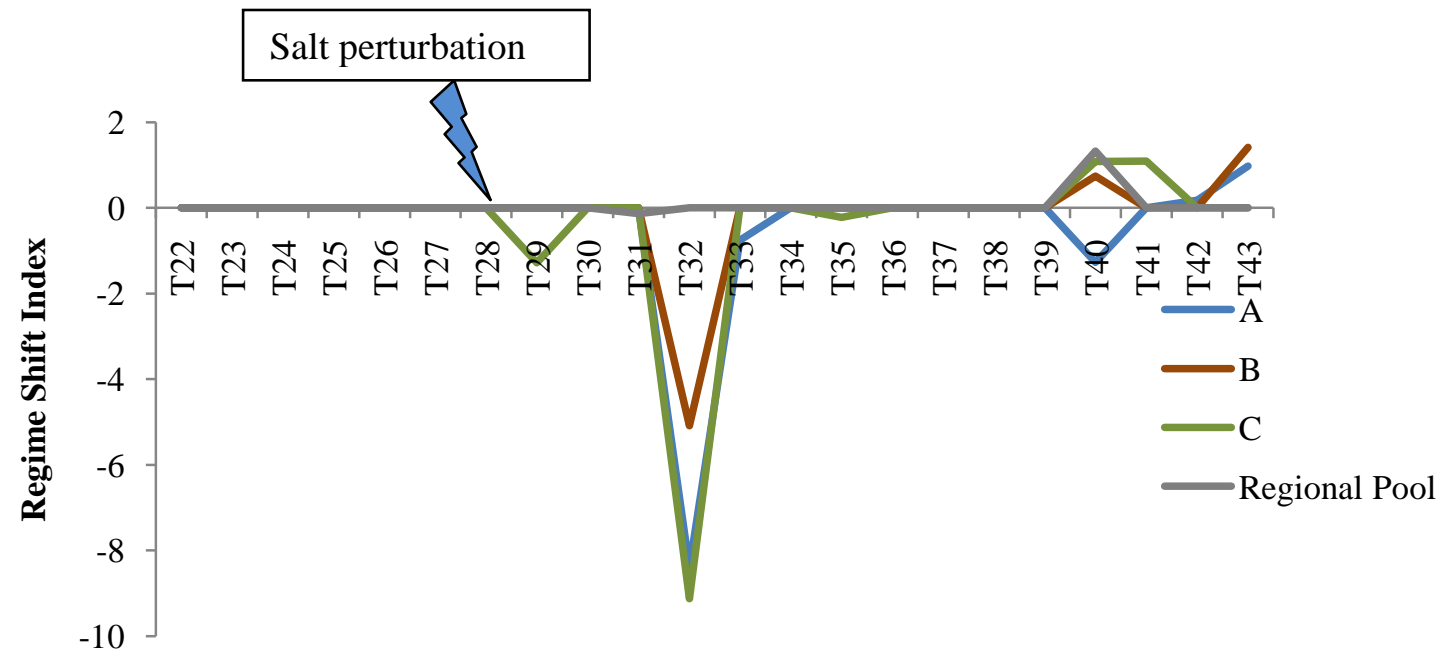

Figure 6. Regime shift index, indicating the direction and the magnitude of the shift one week before and after the salinity shock was applied. Regime shift detection parameters were set to a significance level of 0.05 , a cut-off length of 8 and a Huber's weight parameter of 6 . 


\subsubsection{Biolog Ecoplates}

\subsection{2 (a) Kinetics of the Average Well Colour Development (AWCD)}

Biolog Ecoplates were used to investigate the functional potential of the bacterial communities. The rate at which the substrates of the plates were used (measured by the slope of the linear phase of AWCD) during batch mode cultivation is shown in Figure 7a. The rates of substrates utilization between the three treatments during the batch mode was similar, with no statistically significant differences being observed (ANOVA, $P=0.95$ ).

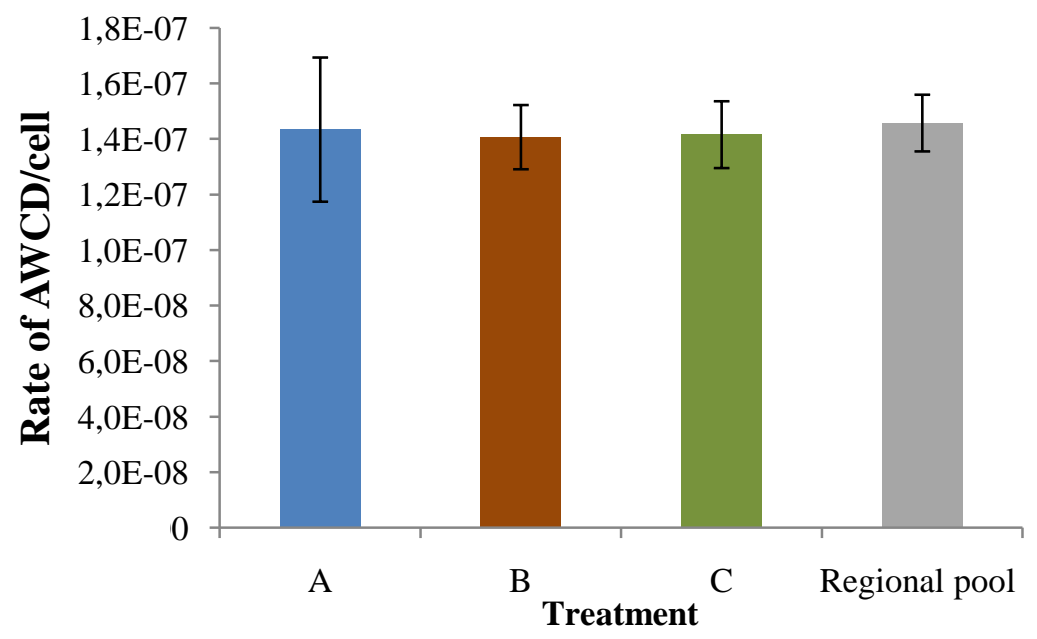

Figure 7a. Average well colour development under batch mode. Rates are normalized with the abundance at the start of the measurement. Error bars indicate standard deviation.

The rates at which the substrates were used during the chemostat mode are shown in Figure 7b. The salt perturbation was found to significantly impair ecosystem functioning (MANOVA, $P<0.001$ ). It was found that no statistically significant differences were observed in the rate of substrates utilization between the treatments, for two time points before the perturbation. However, 24 hours (T29) after the perturbation had occurred, a significant difference was observed between the treatments (Table 2). 
Table 2. Results of Single Factor ANOVA for two time points before and after the perturbation.

ANOVA test

\begin{tabular}{ll}
\hline Time points & p-value \\
\hline${\mathrm{T} 15^{\mathbf{a}}}^{\mathrm{a}}$ & 0.24 \\
$\mathrm{~T} 21^{\mathbf{a}}$ & 0.59 \\
$\mathrm{~T}^{2} 9^{\mathbf{b}}$ & $0.001^{* *}$ \\
$\mathrm{~T}^{\mathrm{b}} 5^{\mathrm{b}}$ & 0.62 \\
\hline a pre-perturbation
\end{tabular}

b post-perturbation

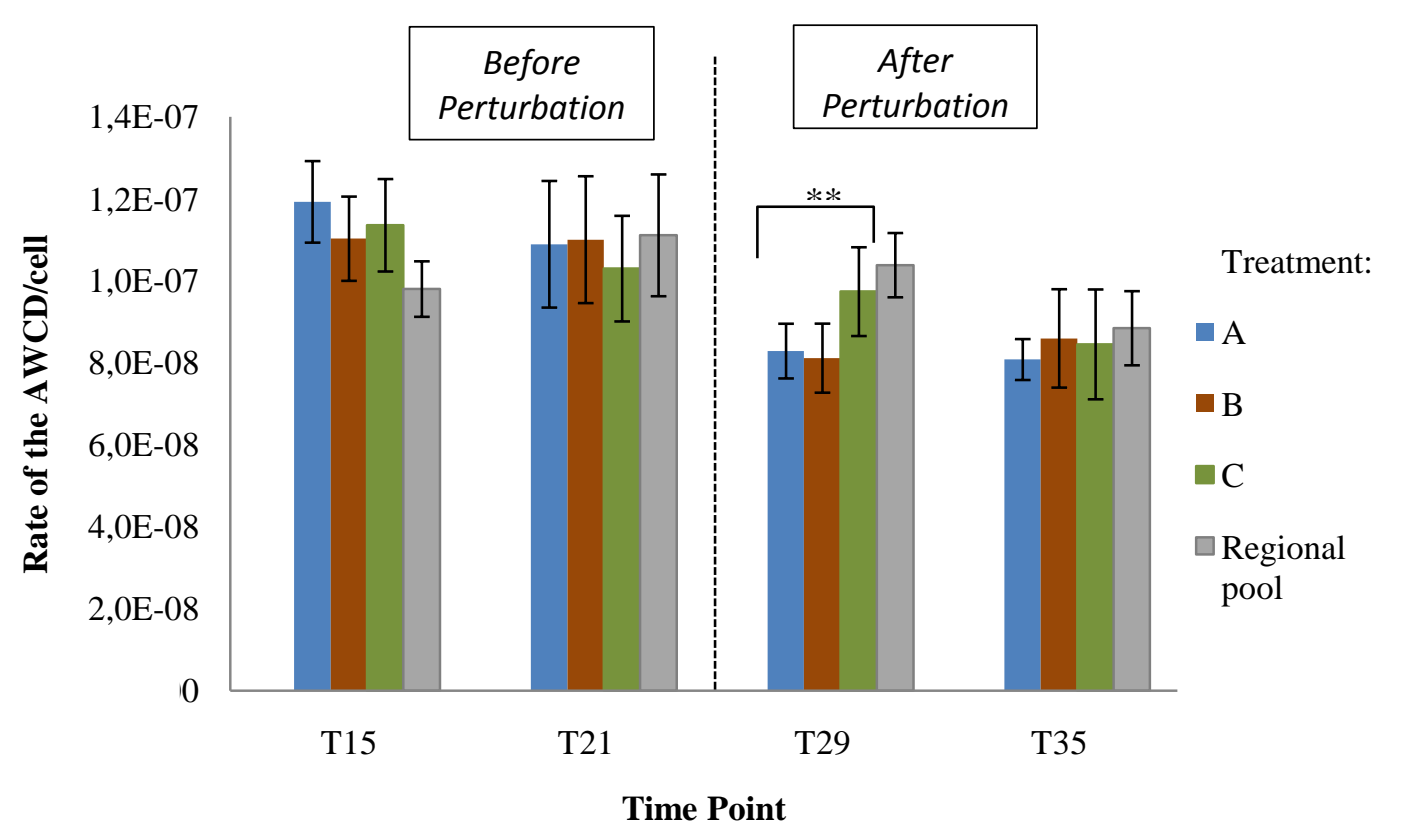

Figure $7 \mathrm{~b}$. AWCD for two times points before and after the perturbation. Rates are normalized with abundance at the start of the measurement. Error bars indicate standard deviation.

Post-hoc (Tukey's test) analysis for T29 (Figure 7c) revealed that the rate at which the substrates were used was significantly higher in treatment $C$ (spatial refuge) that received cells from the undisturbed regional pool, compared to both treatments A (control) and B (temporal refuge). The Tukey's test showed that treatment A was similar to treatment B. 


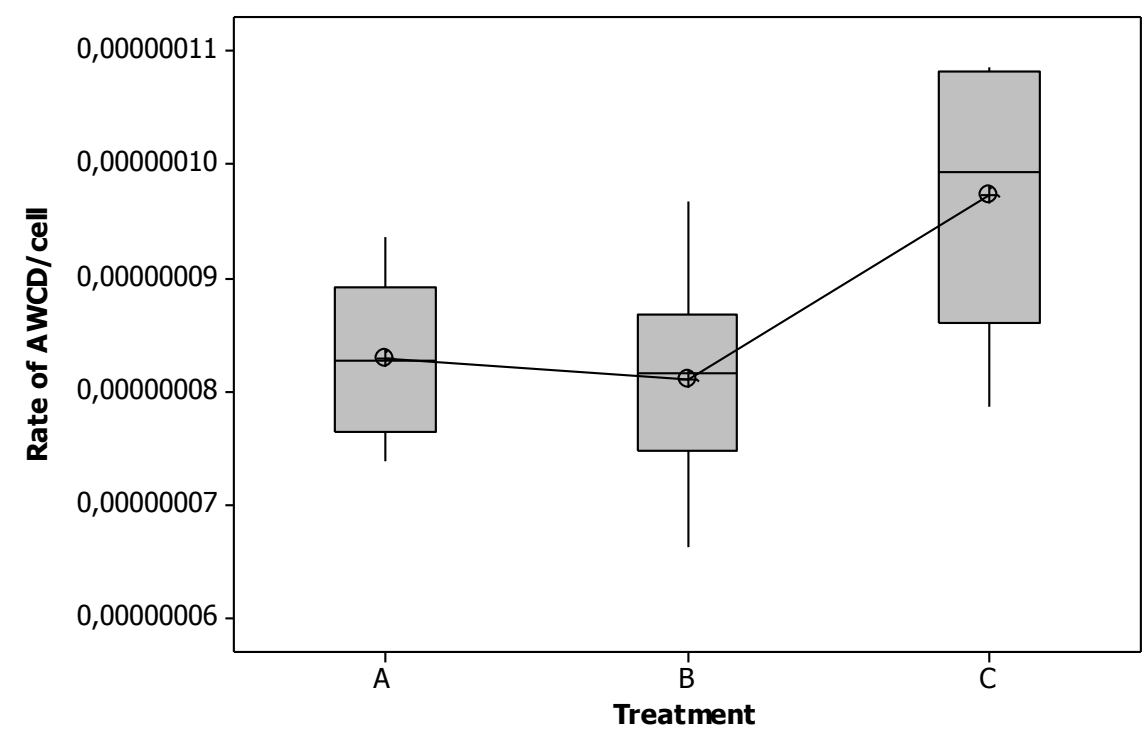

Figure 7c. Mean rate of AWCD at T29. Tukey's test revealed statistically significant differences (ANOVA) of treatment C compared to A and B.

One week after the perturbation (T35) the rates of substrate utilizations were similar for the three treatments. The rate of substrate utilization recovered within one week from the perturbation as no statistically significant differences were observed between the treatments when compared to undisturbed regional pool (Table 3).

Table 3. Results of independent T-test for the rates of substrate utilization for the three respective treatments compared to the undisturbed regional pool to determine resiliency.

T-test

\begin{tabular}{ll}
\hline Treatment & p-value \\
\hline A & 0.095 \\
B & 0.764 \\
C & 0.700 \\
\hline
\end{tabular}




\subsection{2 (b) Pattern in substrate use}

Principal component analysis (PCA) was performed on the data derived from the Biolog measurements to investigate the patterns of substrate use between the three treatments for two times points before and after the perturbation, respectively. We observed a gradual change in substrate utilization from T15-T35 (Figure 8). A closer look shows that before the perturbation (at time point $\mathrm{T} 15$ and $\mathrm{T} 21$ ) the way the bacterial communities used the substrates between the treatments was similar to the regional pool, since the distance from the treatments to $\mathrm{R}$ is relatively small in the ordination. After the perturbation (at T29 and T35), the way how the bacterial communities utilize the carbon substrates of the Biolog greatly diverged compared the un-disturbed regional pool, shown by the increase in distance between the treatments and R. On T35 the divergence was greater than at T29, but in both cases treatment C (Spatial refuge) was closer to the undisturbed regional pool. At T29 (after the perturbation) it was observed that treatment A (control) and B (temporal refuge) was closed to each other and had a similar relative distance to the regional pool, however on T35 treatment A was closer to the regional pool compared to treatment B.

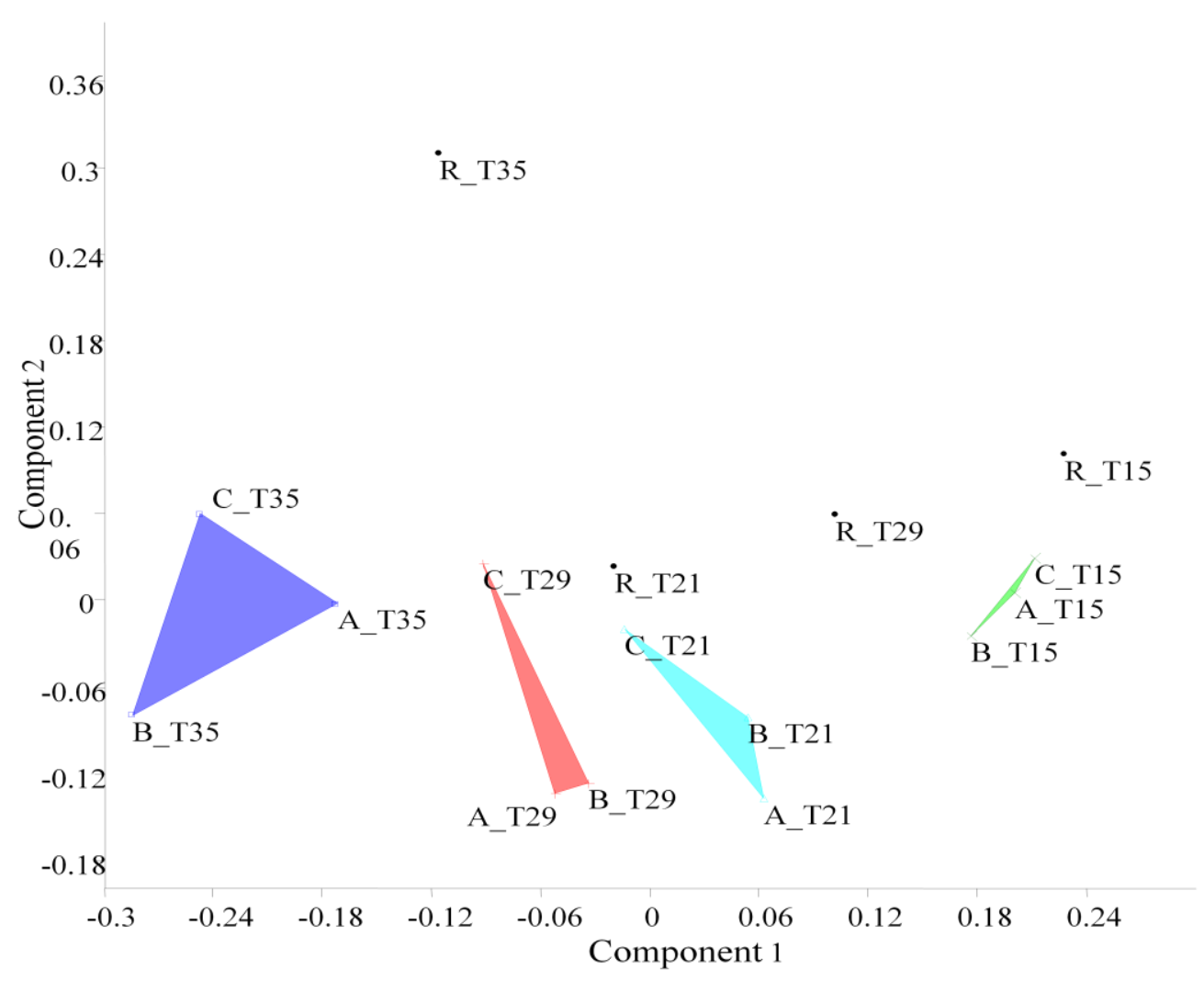

Figure 8. Principal component analysis (PCA) of the substrates utilization pattern. 


\subsubsection{Respiration}

During batch mode (Figure 9a), the rates of respiration (measured as the consumption of dissolved oxygen $\mathrm{mg} / \mathrm{l}$ ) were similar for the three treatments (ANOVA, $P<0.65$ ).

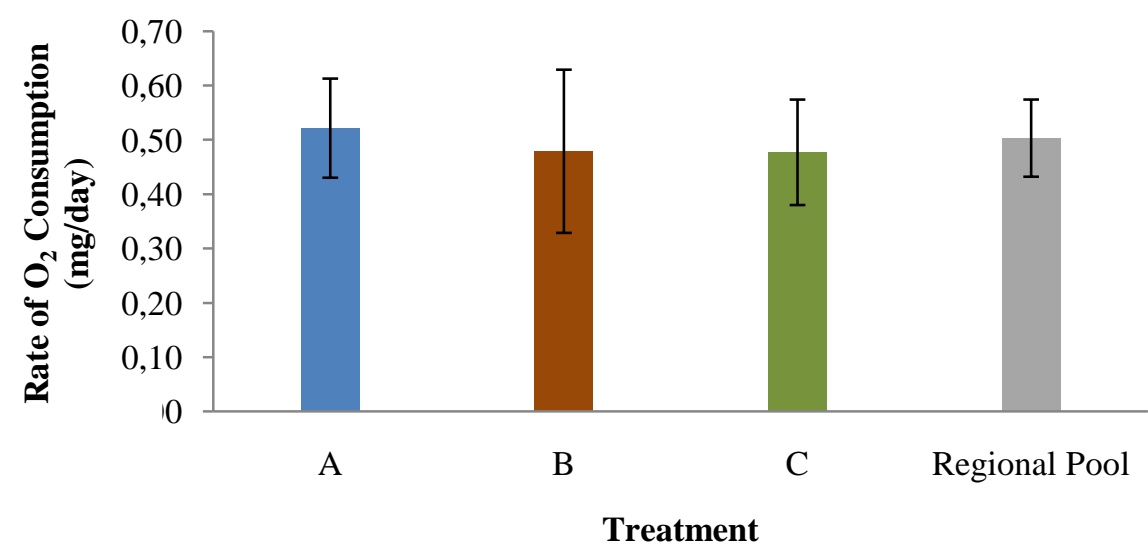

Figure 9a. Respiration rate during batch cultivation mode. Error bars indicate standard deviation.

The respiration rates recorded during the chemostat mode are shown in Figure $9 \mathrm{~b}$. The disturbance was also found to decrease the respiration rates (MANOVA, $P<0.001$ ). No statistically significant differences were observed at the two time points before the perturbation (Table 4), however directly after the perturbation (at time point T29) treatment C (spatial refuge), which received cells from the un-disturbed regional pool, had a significantly higher (Figure 9c) respiration rate compared to treatments A and B. The Tukey's test also revealed that treatment B (temporal refuge) had a slightly higher respiration rate compared to treatment A (control: no refuge). One week after the perturbation was applied (T35), ecosystem functioning measured in terms of respiration rate was similar for treatment $\mathrm{B}$ (temporal refuge) and $\mathrm{C}$ (spatial refuge), which recovered from the disturbance when compared to the undisturbed regional pool (control). Treatment A (no refuge) did not appear to recover compared to both treatments B and C (Table 5). 
Table 4. Results of Single Factor ANOVA for respiration rate before and after the perturbation

ANOVA test

\begin{tabular}{ll}
\hline Time points & p-value \\
\hline T15 $^{\mathbf{a}}$ & 0.215 \\
$\mathrm{~T}^{2} 1^{\mathbf{a}}$ & 0.07 \\
$\mathrm{~T}^{2} 9^{\mathbf{b}}$ & $<0.001^{* *}$ \\
$\mathrm{~T}^{\mathbf{b}}{ }^{\mathbf{b}}$ & 0.08 \\
\hline
\end{tabular}

${ }^{\mathrm{a}}$ pre-perturbation

b post-perturbation

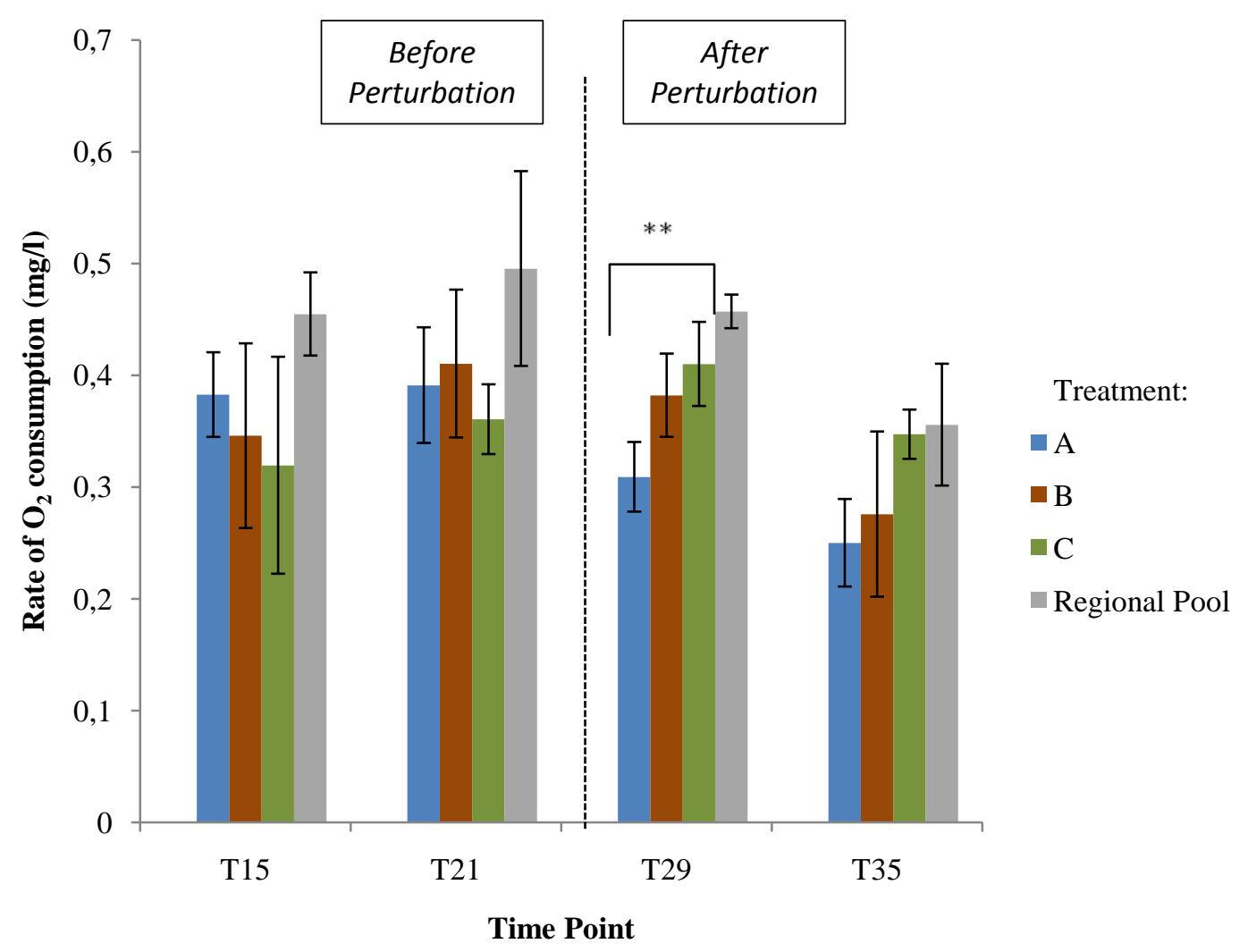

Figure 9b. Respiration rate (measured as oxygen consumption rate) before and after the disturbance. Error bars indicate standard deviations. 


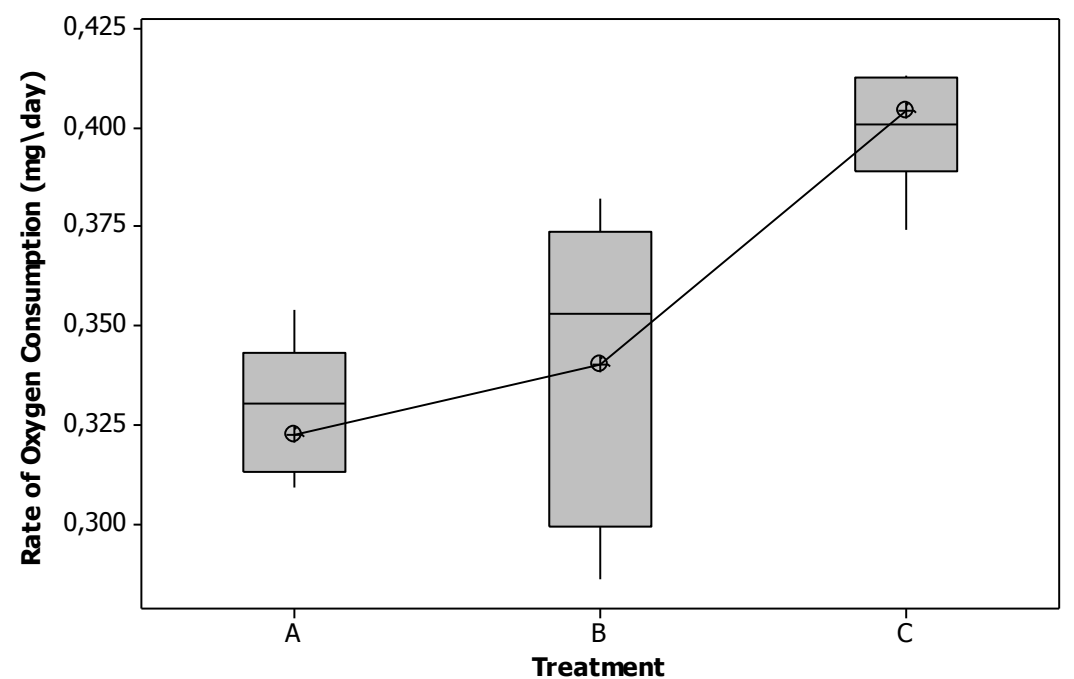

Figure 9c. Tukey's test of respiration rate immediately after the perturbation at time point T29

Table 5. Results of independent T-test performed on the rate of oxygen consumption (respiration) for the three treatments compared undisturbed regional pool to determine resiliency.

$$
\text { T-test }
$$

\begin{tabular}{ll}
\hline Treatment & p-value \\
\hline A & 0.004 \\
B & 0.119 \\
C & 0.912 \\
\hline
\end{tabular}

\subsection{Bacterial community composition}

On average the number of OTU's detected by TRFLP ranged from 39 to 81 for the samples treated with the restriction enzymes $\operatorname{hinf} 1$ and hae 1 .

Non-metric multidimensional scaling (nMDS) analysis (Figure 10a) performed on the bacterial community composition data revealed that lake bacterial communities differed from that of the inoculum, which reflects the effect of filtration when the bacterial inoculum was prepared for the experiment. The communities that developed at time point: T28, T29, T31 and T43 were similar to each other. However the bacterial communities at T8 were different when compared to the other time points. It was also observed that the bacterial communities 
which colonised the biochips were similar to those present in the pelagic phase (free floating bacterial communities) of treatment B (temporal refuge) at time point T43.

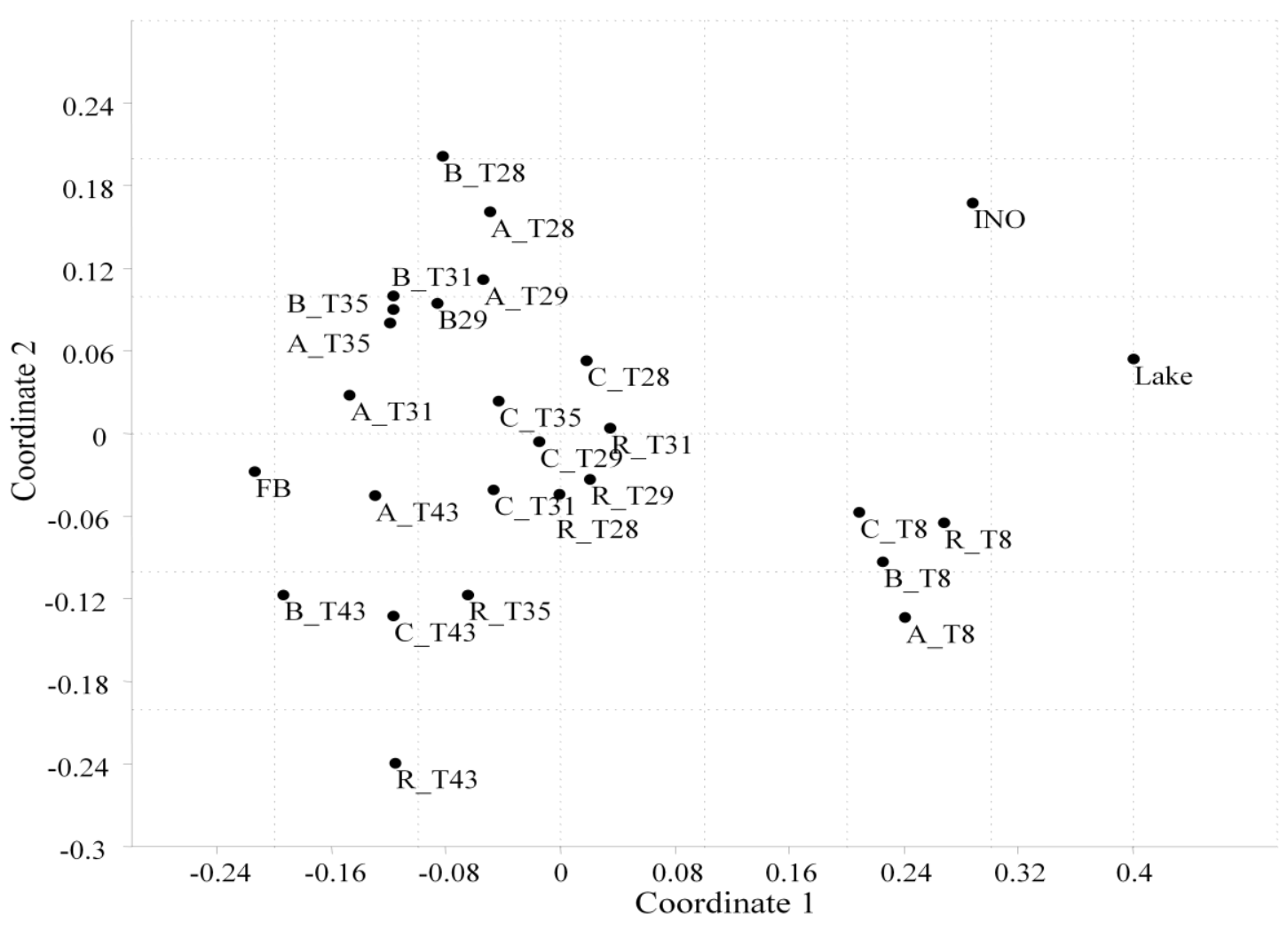

Figure 10a. Non-metric multidimensional scaling (Coordinate 1 against Coordinate 2) of Bray Curtis similarity distance matrices calculated from bacterial community for all data, including the lake original, inoculum and the treatments according to their respective sampling dates. Lake: Original Bacterial Community found in the lake INO: Community present in the inoculums A: No refuge $\mathbf{B}$ : Temporal refuge C: Spatial refuge R: Regional Pool FB: Bacterial communities developed on the Biochips (Treatment B) The numbers indicate the sampling dates.

The difference observed in bacterial community composition between T8 and the other time points (shown in Figure 10b), indicate that the establishment of communities were influenced by duration of the experiment, meaning that the chemostat cultivation technique had an effect on the bacterial communities compositions. 


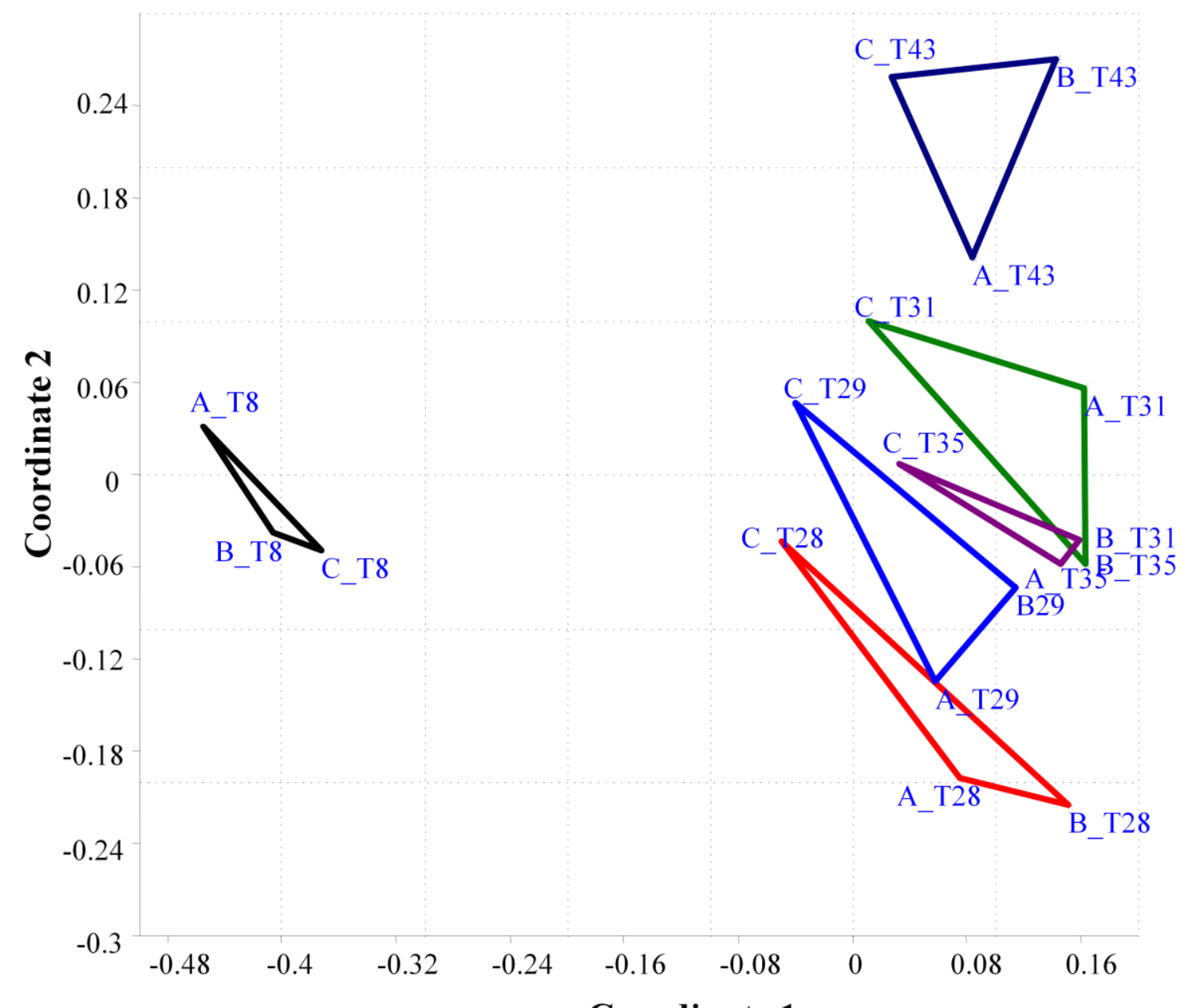

Coordinate 1

Figure 10b. Non-metric multidimensional scaling (Coordinate 1 against Coordinate 2) of Bray Curtis similarity distance matrices calculated from bacterial community including only the treatment data.

On the other hand, the effects of the treatments (A: no refuge, B: Temporal refuge and C: Spatial refuge) on the composition were outlined (Figure 10c) when coordinate 2 against coordinate 3 of the NMDS were considered. The bacterial communities in the three treatments were similar to each other at the beginning of the chemostat cultivation mode, however with time differences in community composition appeared. Treatment B (temporal refuge) was observed to overlap slightly with treatment A (no refuge) as well as treatment $\mathrm{C}$ (spatial refuge). The bacterial communities in treatment $\mathrm{C}$ were very similar to the undisturbed regional pool whereas treatment $\mathrm{B}$ overlapped to some extent with the unperturbed regional pool. At the end of the experiment (on T43) it was observed that the bacterial communities in both treatments $\mathrm{B}$ and $\mathrm{C}$ were very similar to the undisturbed regional pool compared to 
treatment A whereas a substantial dissimilarity was noted, when comparing the communities of treatment A to that of the undisturbed regional pool.

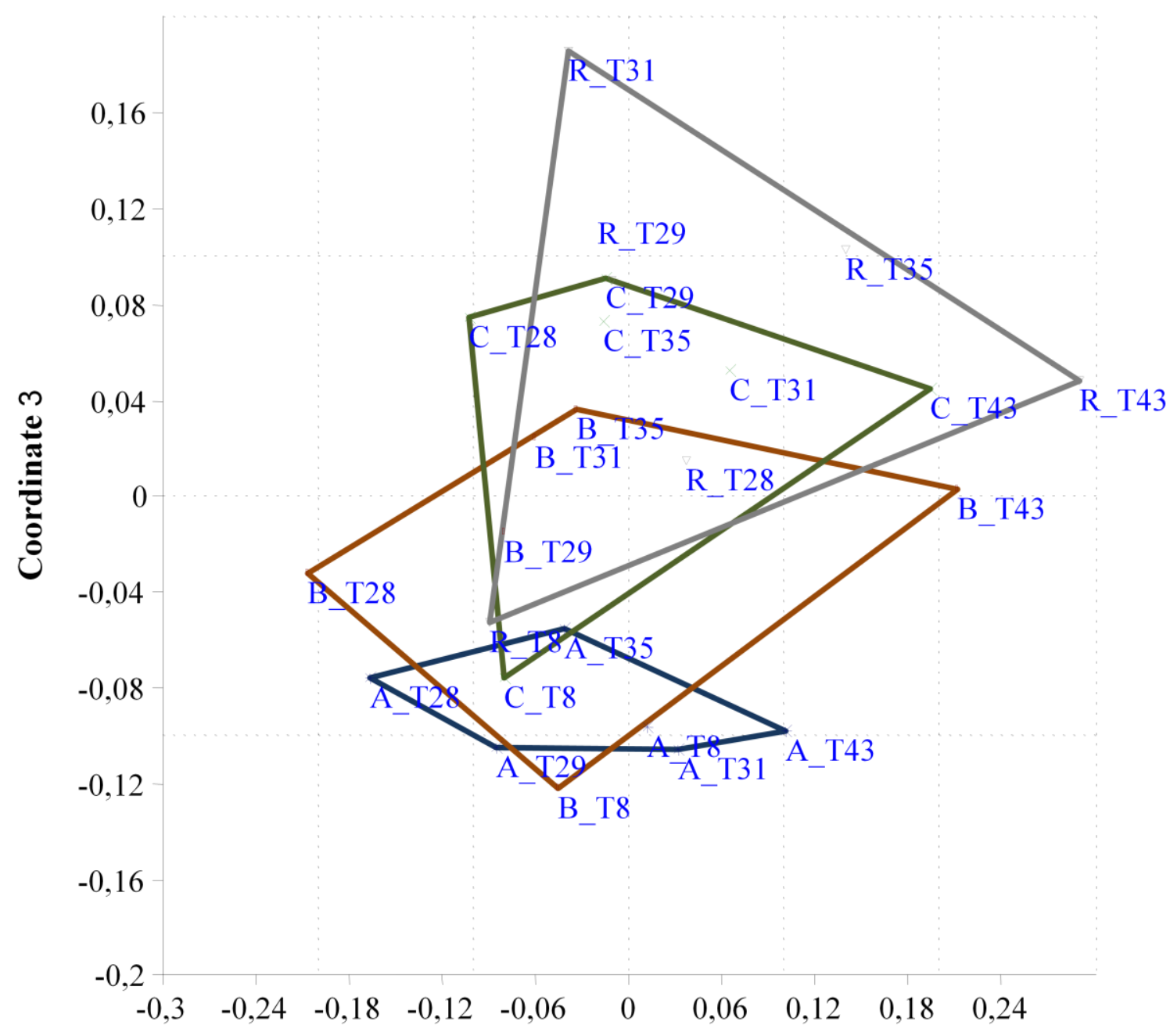

\section{Coordinate 2}

Fig 10c. Non-metric multidimensional scaling (Coordinate 2 against Coordinate 3) of Bray Curtis similarity distance matrices, showing the effects of the three treatments and the undisturbed regional pool (only treatment data included in the analysis).

Further analysis was performed on the second coordinates where the effects of the treatments were revealed. The score of the second axis of a Principal Component Analysis (PCA) was used to determine regime shift in community composition induced by the salt perturbation. The purpose of using PCA was to generate single values out of the multivariate, average communities generate by the T-RFLP. Like for the abundance data, the regime shift detection algorithm (Rodionov 2004) was applied on the PCA scores. The results of the regime shift detection are shown in Figure 11a-c. In treatment A (no refuge), a regime shifts was detected 
on T29. In treatment B (temporal refuge), two regime shifts were detected, one on T29 and another one on T43. In treatment $\mathrm{C}$ (Spatial refuge), using the same settings as for the other treatments, no regime shift was detected after being disturbed by the perturbation.

\section{A}

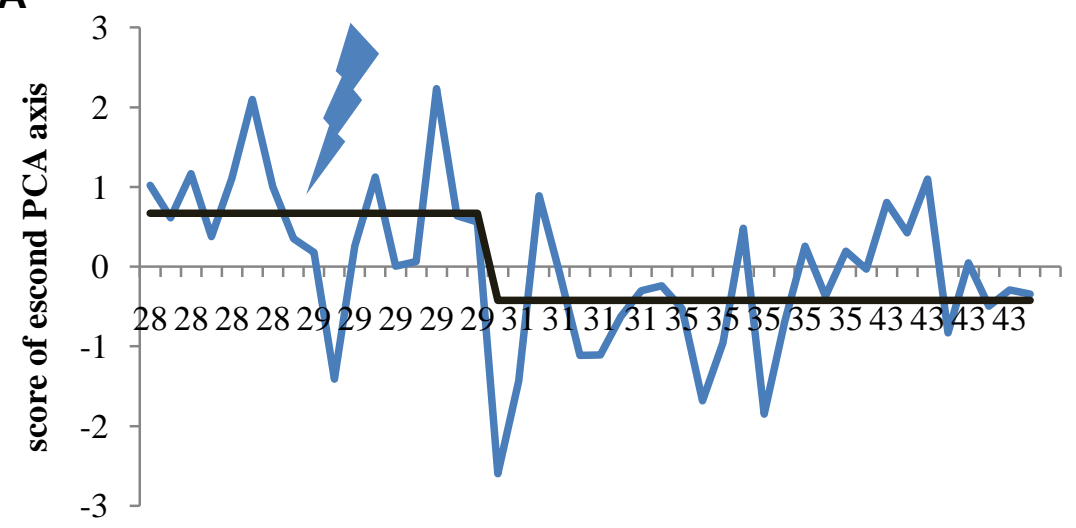

B

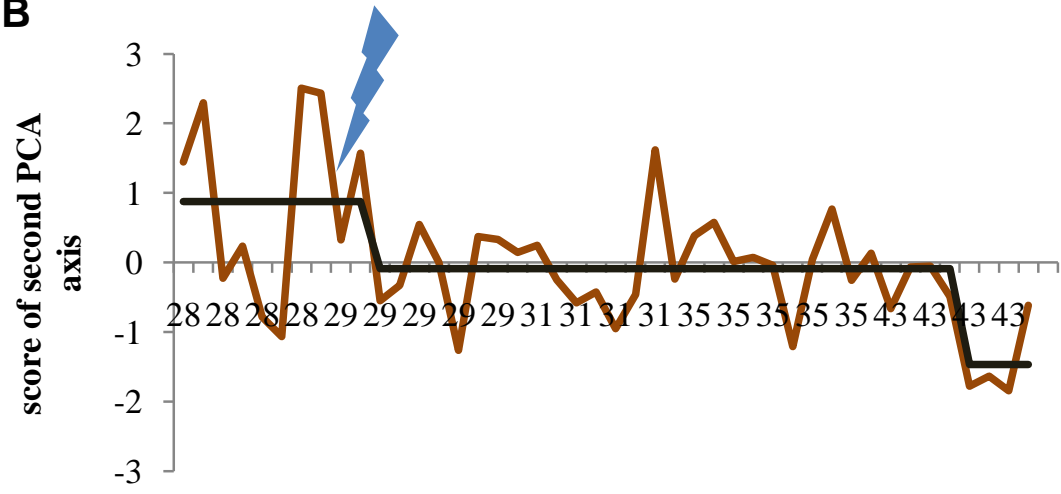

C

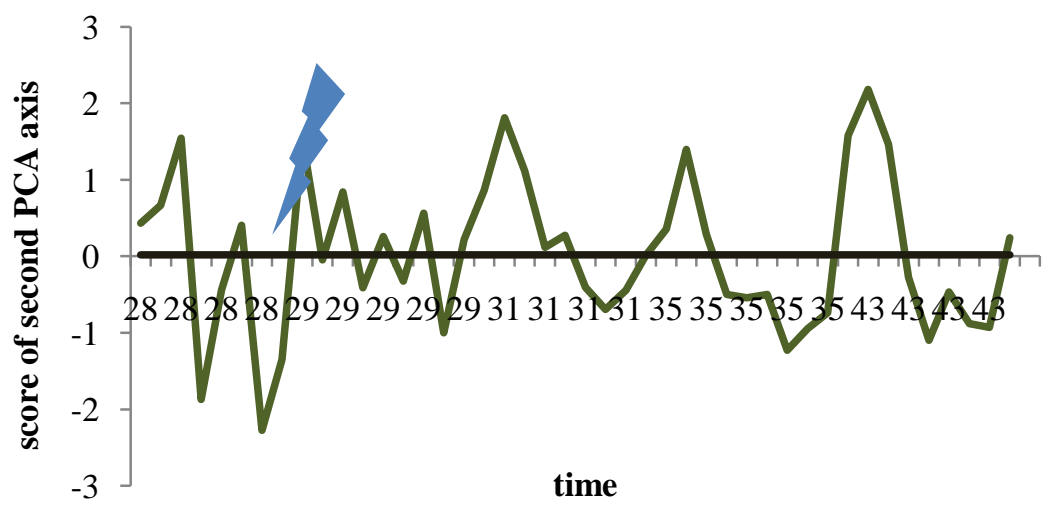

Figure 11. Regime shift detection for treatment A (no refuge), treatment B (temporal refuge) and treatment $\mathrm{C}$ (spatial refuge). The colored lines are the scores of the second PCA axis for each replicated sample at each timepoint (T28-T43), the black lines indicate the means before or after a regime shift. Treatment A lacks a shift in community composition was observed on T29. Treatment B (temporal refuge) showed that the communities two shifts in community composition one on T29 and the second one on T43 while treatment $\mathrm{C}$ (spatial refuge) did not shift in community composition. Regime shift detection was set to significance level of 0.05 , with a cut-off length of 9 and a Huber's weight parameter of 6 . 


\section{Discussion}

In this experiment, chemostat cultivation technique was used to investigate how the provision of two types of refuges: temporal and spatial, influenced the resistance and resilience of microbial communities compared to a treatment which did not offer a refuge. In general, we found that the salt perturbation was able to significantly affect microbial community in composition and functioning. Such sudden changes in salinity might not be very common in nature, however it might be useful to understand the general ecological mechanisms involved in resistance and resilience of microbial communities against pulse disturbances. Understanding how communities react to stress can be particularly useful to predict and manage the impacts of disturbances with the objective of preserving ecosystem functioning. As Allison and Martiny (2008) point out, perturbations might affect community composition and functioning in a variety of ways. However, in natural conditions, dispersal between communities (metacommunity framework) might not only shape communities but can also enhance resistance and resilience against perturbations, similarly Bengtsson et al. (2003) recognised the importance of dispersal which the author termed "external memory" to maintain resistance or resilience against disturbances, which has implications for environmental management.

In treatment $\mathrm{A}$ (no refuge) both bacterial functioning (Figure $7 \mathrm{~b}$ and Figure $9 \mathrm{~b}$ ) and community composition (Figure 11a) were affected by the salt pulse disturbance. In this treatment, respiration rate as well as community composition did not show signs of resistance or resilience. Regime shift detection analysis performed on the bacterial abundance (Figure 6) showed that two negative shifts occurred after the perturbation where the abundance was reduce significantly, which might have a considerable impact on the food web in natural ecosystems. In addition, the same regime shift analysis performed on abundance data indicated that both treatments B and C could reach comparable pre-perturb abundances faster than treatment A suggesting that provision of refuges might have a positive effect on bacterial growth. On the other hand, the rate of substrate utilisation recovered within a week. This recovery might be the effect of a high level of functional redundancy in bacterial communities as similar observations were made by Franklin and Mills (2006). An alternative explanation for the recovery in substrate utilisation in treatment $\mathrm{A}$ might be because of metabolic flexibility as observed in one study carried out by Fernandez et al. (2000). The authors found that identical methanogenic communities located in two bioreactors functioned similarly 
before a glucose pulse perturbation was induced however the authors found that communities were able recover from the perturbation by using distinct metabolic pathways. The bacterial communities in treatment $\mathrm{A}$ observed at the end of the experiment were substantially different from that of the undisturbed regional pool (Figure 10c). Further analysis using the regime shift detection algorithm (Figure 11a) performed on the community composition data of treatment $\mathrm{A}$ indicated that the perturbation induced the communities to shift to an alternative stable state. This shift to an alternative state after the perturbation might be accompanied by a reduction in functioning in this case the respiration rate, which might in natural aquatic ecosystems significantly influence the carbon cycle.

In treatment B (which is the temporal refuge where a surface for colonisation was provided) it was found that bacterial functioning (Figure $7 b$ and Figure $9 b$ ) was affected by the perturbation shortly after the perturbation but two of the functioning parameters (substrates utilization and respiration rates) recovered within a week. The community composition of treatment B was affected by the perturbation which was highlighted by the regime shift detection algorithm (Figure 11b), however in contrast with treatment A, treatment B showed a second shift in composition which might indicate that the community was resilient and shifted to a previous state. Similarly, non-metric multidimensional scaling analysis revealed that at the end of the experiment (T43), the bacterial community composition of treatment B (temporal refuge) was similar to the undisturbed regional pool (Figure 10c). According to Bengtsson et al. (2003) ecological memory is an important factor, by which communities can reorganize themselves after experiencing a perturbation and the second shift in community composition observed could highlight the role of the temporal refuge or dormancy in providing ecological memory. Moreover, interactions between those species that were able to establish on the biochips (treatment B) could have provided some degree of physical protection against the salt perturbation, where they could eventually re-colonized the 'pelagic' phase once the salt was washed out of the system.

In treatment $C$ (spatial refuge), bacterial functioning (Figure $7 \mathrm{~b}$ and Figure $9 \mathrm{~b}$ ) was also affected by the perturbation and as in treatment B two of the functioning parameters (substrates utilization and respiration rates) recovered within a week. In contrast to the other treatments it was observed that substrate utilization and respiration rates (Figure $7 \mathrm{c}$ and Figure 9c) was significantly higher immediately after the perturbation. This might indicate that the provision of active, unaffected cells from the region provided some kind of short-termed insurance (resistance) against the salinity stress. The short-termed insurance could be 
explained by two different mechanisms in which the dispersed cells seemed to have an active role either compensate for loss (mortality) caused by the perturbation or maintain positive interactions occurring within the bacterial communities where the presence of one species can allow others to persist thereby maintaining ecosystem functioning (Mulder et al. 2001; Downing and Leibold 2010). Although, we did not test the importance of dispersal rate, it seems reasonable to expect that with an increasing amount of cells dispersed into an environment (mass effects in the language of the metacommunity framework) the potential to buffer perturbations might increase. However there is very little knowledge about actual dispersal rates of bacteria under natural conditions (Logue and Lindström 2008). The regime shift detection algorithm (Figure 11c) did not detect any shift in community composition after being exposed to the disturbance which might indicate that the communities present in the spatial refuge treatment were resistant to the perturbation. The nMDS analysis also showed that the bacterial communities of the treatment $\mathrm{C}$ (spatial refuge) were very similar to the undisturbed regional pool (Figure 10c). The resistance observed in community composition could be linked to the short-termed resistance observed in the functional parameters (more specifically rates in substrate utilization and respiration), which might highlight that those functions are influenced by community composition, in contrast to other studies (Griffiths et al. 2000; Downing and Leibold 2010) which concluded that functioning is mainly affected by species richness.

Perturbations occur frequently in all ecosystems (Naeem and Li 1997), however it is hard to mimic natural ecosystems, in order to understand the complexity of the underlying mechanisms (response of ecosystems against perturbations) through experimental approaches. The chemostat approach compared to batch mode culture maintains the bacterial cells in continuous exponential growth phase and allows the possibility of having a pulse disturbance. Perturbations (e.g. the addition of toxins or sudden changes in environmental conditions like $\mathrm{pH}$ or salinity) are difficult to reverse in batch cultures. On the other hand, chemostat cultivation is known to select for species with an optimal growth rate to adjust to the dilution created by the constant in- and outflow of the medium (Chao et al. 1977). Another disadvantage is that bacteria are known to colonize the wall of cultivation vessels (Ratnam et al. 1982; Ammerman et al. 1984) which might act as a small refuge also in treatment A, however to compensate this effect we used a much larger colonizing surface area provided in the temporal refuge treatment. 


\section{Conclusions and future perspective}

The aim of this study was to investigate how the provision of refuges influences resistance and resilience in microbial communities against a pulsed salt perturbation. Over the last decade, several studies highlighted the importance of diversity on ecosystem functioning however the role of refuges in buffering the effects of environmental changes is not well known. A detailed understanding of the mechanism involved could be particularly useful to predict and manage the impact of disturbances especially in face of the challenges imposed by global climate change. Our findings indicate that the provision of a temporal and a spatial refuge can influence resistance and resilience of microbial communities. However, in nature communities other factors such as dormancy (Jones and Lennon 2010) might be equally important for buffering the effects of disturbances and to maintain microbial diversity. 


\section{Acknowledgements}

I would like to express my deepest gratitude for the precious advices and continuous assistance of my supervisors: Hannes Peter and Lars Tranvik, throughout the project. A special thank to Xinmei Feng, for her collaboration on the PCR work and for the constructive comments of my opponents: Jerôme Comte and David Cayon. A very special thank for the support and the encouragements of my friends and my relatives especially to Pia-Maria Öqvist. 


\section{References:}

Agogué, H., Joux, F., Obernosterer, I. and Lebaron, P. (2005). Resistance of Marine Bacterioneuston to Solar Radiation. Applied and Environmental Microbiology, 71(9): 52825289.

Allison, S.D. and Martiny, J.B.H. (2008). Resistance, resilience and redundancy in microbial communities. Proceedings of the National Academy of Sciences of the United States of America, 105: 11512-11519.

Ammerman, J.W., Fuhrman, J.A., Hagström, Å. and Azam, F. (1984). Bacterioplankton growth in seawater: I. Growth kinetics and cellular characteristics in seawater cultures. Marine Ecology Progress Series, 18: 31-39.

Balvanera, P., Pfisterer, A.B., Buchmann, N., He, S.F., Nakashizuka, T., Raffaelli, D. and Schmid, D. (2006). Quantifying the evidence for biodiversity effects on ecosystem functioning and services. Ecology Letters, 9: 1146-1156.

Beisner, B.E., Haydon, D.T. and Cuddington, K. (2003). Alternative stable states in ecology. Frontiers in Ecology and the Environment, 1(7): 376-382.

Bell, T., Newman, J.A., Silverman, B.W., Turner, S.L. and Lilley A.K. (2005). The contribution of species richness and composition to bacterial services. Nature, 436: 11571160 .

Bengtsson, J., Angelstam, P., Elmqvist, T., Emanuelsson, U., Folke, C., Ihse, M., Moberg, F. and Nyström, M. (2003). Reserves, Resilience and Dynamic Landscapes. Ambio, 32(6): 389396.

Cardinale, B.J., Srivastava, D.S., Duffy J.E., Wright, J.P., Downing, A.L., Sankaran, M. and Jouseau, C. (2006). Effects of biodiversity on the functioning of trophic groups and ecosystems. Nature, 443: 989-992.

Chaer, G., Fernandes, M., Myrold, D. and Bottomley, P. (2009). Comparative Resistance and Resilience of Soil Microbial Communities and Enzyme Activities in Adjacent Native Forest and Agricultural Soils. Microbial Ecology, 58: 414-424.

Chao, L., Levin, B.R. and Stewart, F.M. (1977). A complex community in a simple habitat: An experimental study with Bacteria and Phase. Ecology, 58: 369-378.

Comte, J. and del Giorgio, P.A. (2009). Links between resources, C metabolism and the major components of bacterioplankton community structure across a range of freshwater ecosystems. Environmental Microbiology, 11(7): 1704-1716.

Crump, B.C. and Hobbie J.E. (2005). Synchrony and seasonality in bacterioplankton communities of two temperate rivers. Limnology and Oceanography, 50(6): 1718-1729.

Curtis, T.P., Head, I.M., Lunn M., Woodcock, S., Schloss, P.D. and Sloan, W.T. (2006). What is the extent of prokaryotic diversity? Philosophical Transactions of the Royal Society B, 361: 2023-2037. 
de Haan, H., Jones, R.I. and Salonen, K. (1987). Does ionic strength affect the configuration of aquatic humic substances, as indicated by gel filtration? Freshwater Biology, 17: 453-459 Cited in Logue, J.B. and Lindström, E.S. (2008). Biogeography of bacterioplankton in inland waters. Freshwater Reviews, 1: 99-114.

del Giorgio, P.A. and Bouvier, T.C. (2002). Linking the physiologic and phylogenetic successions in free-living bacterial communities along an estuarine salinity gradient. Limnology and Oceanography, 47(2): 471-486.

del Giorgio, P.A., Bird, D.F., Prairie, Y.T. and Planas, D. (1996). Flow cytometric determination of bacterial abundance in lake plankton with the green nucleic acid stain SYTO 13. Limnology and Oceanography, 41: 783-789.

DeLong, E.F. and. Pace, N.R. (2001). Environmental Diversity of Bacteria and Archaea. Systematic Biology, 50(4): 470-478.

Descy, J.P. and Sarmento, H. (2008). Microorganisms of the East African Great Lakes and their response to environmental changes. Freshwater Reviews, 1: 59-73.

Downing, A.L. and Leibold, M.A. (2010). Species richness facilitates ecosystem resilience in aquatic food webs. Freshwater Biology, 55: 2123-2137.

Eiler, A., Langenheder, S., Bertilsson, S. and Tranvik, L.J. (2003). Heterotrophic Bacterial Growth Efficiency and Community Structure at Different Natural Organic Carbon Concentrations. Applied and Environmental Microbiology, 69(7): 3701-3709.

Elmqvist, T., Folke, C., Nyström, M., Peterson, G., Bengtsson, J., Walker, B. and Norberg, J. (2003). Response diversity, ecosystem change, and resilience. Frontiers in Ecology and the Environment, 1(9): 488-494.

Fernandez, A.S., Hashsham, S.A., Dollhopf, S.L., Raskin, L., Glagoleva, O., Dazzo, F.B., Hickey, R.F., Criddle, C.S. and Tiedje, J.M. (2000). Flexible Community Structure Correlates with Stable Community Function in Methanogenic Bioreactor Communities Perturbed by Glucose. Applied and Environmental Microbiology, 66(9): 4058-4067.

Franklin, R.B. and Mills, A.L. (2006). Structural and Functional Responses of a Sewage Microbial Community to Dilution-Induced Reductions in Diversity. Microbial Ecology, 52: 280-288.

Garland, J.L. and Mills, A.L. (1991). Classification and characterization of heterotrophic microbial communities on the basis of patterns of community-level-sole-carbonsource utilization. Applied and Environmental Microbiology, 57: 2351-2359.

Garland, J.L., Mills, A.L. and Young, J.S. (2001). Relative effectiveness of kinetic analysis vs single point readings for classifying environmental samples based on community-level physiological profiles (CLPP). Soil Biology and Biochemistry, 33: 1059-1066.

Glasby, T.M. and Underwood, A.J. (1996). Sampling to differentiate between pulse and press perturbations. Environmental Monitoring and Assessment, 42: 241-252. 
Griffiths, B.S., Ritz, K., Bardgett, R.D., Cook, R., Christensen, S., Ekelund, F., Sørensen, S.J., Bååth, E., Bloem, E., de Ruiter, P.C., Dolfing, J. and Nicolardot, B. (2000). Ecosystem response of pasture soil communities to fumigation-induced microbial diversity reductions: an examination of the biodiversity-ecosystem function relationship. Oikos, 90: 279-294.

Holling, C.S. (1973). Resilience and stability of ecological systems. Annual review of ecology and systematics 4: 1-23.

Hooper, D.U., Chapin, F.S., Ewel, J.J., Hector, A., Inchausti, P., Lavorel, S., Lawton, J.H., Lodge, D.M., Loreau, M., Naeem, S., Schmid, B., Setälä, H., Symstad, A.J., Vandermeer, J. and Wardle, D.A. (2005). Effect of biodiversity on Ecosystem Functioning: A consensus of current knowledge. Ecological Monographs, 75(1): 3-35.

Horner-Devine, M.C., Leibold, M.A., Smith, V.H. and Bohannan, B.J.M. (2003). Bacterial diversity patterns along a gradient of primary productivity. Ecology Letters, 6: 613-622.

Jones, S.E. and Lennon, J.T. (2010). Dormancy contributes to the maintenance of microbial diversity. Proceedings of the National Academy of Sciences of the United States of America, 107(13): 5881-5886.

Jürgens, K. and Matz, C. (2002). Predation as a shaping force for the phenotypic and genotypiccomposition of planktonic bacteria. Antonie van Leeuwenhoek, 81: 413-434.

Kirchman, D.L., Dittel, A.I., Findlay, S.E.G. and Fischer, D. (2004). Changes in bacterial activity and community structure in response to dissolved organic matter in the Hudson River, New York. Aquatic Microbial Ecology, 35: 243-257.

Konopka, A., Oliver, L. and Turco, Jr.R.F. (1998). The Use of Carbon Substrate Utilization Patterns in Environmental and Ecological Microbiology. Microbial Ecology, 35: 103-115.

Kühl, M. (2005). Optical Microsensors for Analysis of Microbial Communities. Methods in Enzymology, 397: 166-199.

Kühl, M. and N.P. Revsbech. (2001). Biogeochemical microsensors for boundary layer studies. In: B. P. Boudreau and B. B. Jørgensen (eds.), The Benthic Boundary Layer. Oxford University Press, Oxford. Cited in: Kühl, M. (2005). Optical Microsensors for Analysis of Microbial Communities. Methods in Enzymology, 397: 166-199.

Langenheder, S., Lindstrom, S.E. and Tranvik, L.J. (2005). Weak coupling between community composition and functioning of aquatic bacteria. Limnology and Oceanography, 50(3): 957-967.

Leibold, M.A., Holyoak, M., Mouquet, N., Amarasekare, P., Chase, J.M., Hoopes, M.F., Holt, R.D., Shurin, J.B., Law, R., Tilman, D., Loreau, M. and Gonzalez, A. (2004). The metacommunity concept: a framework for multi-scale community ecology. Ecology Letters, 7: 601-613.

Lindström, E.S. and Leskinen, E. (2002). Do Neighboring Lakes Share Common Taxa of Bacterioplankton? Comparison of $16 \mathrm{~S}$ rDNA Fingerprints and Sequences from Three Geographic Regions. Microbial Ecology, 44: 1-9. 
Logue, J.B. and Lindström, E.S. (2008). Biogeography of bacterioplankton in inland waters. Freshwater Reviews, 1: 99-114.

Loreau, M. (2000). Biodiversity and ecosystem functioning: recent theoretical advances. Oikos, 91: 3-17.

Loreau, M., Naeem, S., Inchausti, P., Bengtsson, J., Grime, J.P., Hector, A., Hooper, D.U., Huston, M.A., Raffaelli, D., Schmid, B., Tilman, D and Wardle, D.A. (2001) Ecology Biodiversity and ecosystem functioning: Current knowledge and future challenges. Science 294:804-808

Mason, N.W.H., Wilson, J.B. and Steel, J.B. (2007). Are alternative stable states more likely in high stress environments? Logic and available evidence do not support Didham et al. 2005. Oikos, 116: 353-357.

Miki, T. and Jacquet, S. (2008). Complex interaction in the Microbial world: underexplored key links between viruses, bacteria and protozoan grazers in aquatic environments. Aquatic Microbial Ecology, 51: 195-208.

Mulder, C.P.H., Uliassi, D.D. and Doak, D.F. (2001). Physical stress and diversityproductivity relationships: The role of positive interactions. Proceedings of the National Academy of Sciences of the United States of America, 98(12): 6704-6708.

Naeem, S. (1998). Species redundancy and ecosystem reliability. Conservation Biology, 12(1): 39-49.

Naeem, S. and Li, S.B. (1997). Biodiversity enhances ecosystem reliability. Nature, 390: 507-509.

Pedrós-Alió, C. (2006). Marine microbial diversity: can it be determined? TRENDS in Microbiology, 14(6): 257-263.

Pernthaler, J. and Posch, T. (2009). Microbial food webs. Encyclopedia of inland waters, 3: 244-251.

Petraitis, P.S. and Dudgeon, S.R. (2004). Detection of alternative stable states in marine communities. Journal of Experimental Marine Biology and Ecology, 300: 343-371.

Purvis, A. and Hector, A. (2000). Getting the measure of biodiversity. Nature, 405: 212-219.

Ratnam, D.A., Pavlou, S. and Fredrickson A.G. (1982). Effects of attachment of bacteria to chemostat walls in a microbial predator-prey relationship. Biotechnology and Bioengineering, 24(12): 2675-2694.

Rodionov, S.N. (2004). A sequential algorithm for testing climate regime shifts. Geophysical Research Letters, 31: 1-4.

Rosselló-Mora, R. and Amann, R. (2001). The species concept for prokaryotes. FEMS Microbiology Reviews, 25: 39-67. 
Scheffer, M., Carpenter, S., Foley, J.A., Folke, C. and Walker, B. (2001). Catastrophic shifts in ecosystems. Nature, 413: 591-596.

Schwartz, M.W., Brigham, C.A., Hoeksema, J.D., Lyons, K.G., Mills, M.H. and van Mantgem, P.J. (2000). Linking biodiversity to ecosystem function: implications for conservation ecology. Oecologia, 122: 297-305.

Warnecke, F., Sommaruga, R., Sekar, R., Hofer, J.S. and Pernthaler, J. (2005). Abundances, Identity, and Growth State of Actinobacteria in Mountain Lakes of Different UV Transparency. Applied and Environmental Microbiology, 71(9): 5551-5559.

Weinbauer, M.G. and Rassoulzadegan, F. (2004). Are viruses driving microbial diversification and diversity? Environmental Microbiology, 6(1): 1-11.

Wertz, S., Degrange, V., Prosser, J.I., Poly, F., Commeaux, C., Guillaumaud, N. and Le Roux, X. (2007). Decline of soil microbial diversity does not influence the resistance and resilience of key soil microbial functional groups following a model disturbance. Environmental Microbiology, 9: 2211-2219.

Whitman, W.B., Coleman, D.C. and Wiebe, W.J. (1998). Prokaryotes: The unseen majority. Proceedings of the National Academy of Sciences of the United States of America, 95: 65786583.

Wilson, D.S. (1992). Complex Interactions in Metacommunities, with Implications for Biodiversity and High Levels of Selection. Ecology, 73: 1984-2000.

Winter, C., Bouvier, T., Weinbauer, M.G. and Thingstad T.F. (2010). Trade-Offs between Competition and Defence Specialist among Unicellular Planktonic Organisms: "Killing the Winner" Hypothesis Revisited. Microbiology and Molecular Biology Reviews, 74(1): $42-57$.

Yachi, S. and Loreau, M. (1999). Biodiversity and ecosystem productivity in a fluctuating environment: The insurance hypothesis. Proceedings of the National Academy of Sciences of the United States of America, 96: 1463-1468.

Yannarell, A.C. and Kent, A.D. (2009). Bacteria, Distribution and community structure Encyclopedia of inland waters, 3: 201-210.

Yannarell, A.C., Kent, A.D., Lauster, G.H., Kratz, T.K. and Triplett, E.W. (2003). Temporal patterns in bacterial communities in three temperate lakes of different trophic status. Microbial Ecology, 46: 391-405.

Zwart, G., Crump, B.C., Agterveld, M.P.K.V., Hagen, F. and Han S.K. (2002). Typical freshwater bacteria: an analysis of available 16S rRNA gene sequences from plankton of lakes and rivers. Aquatic Microbial Ecology, 28: 141-155. 